NBER WORKING PAPER SERIES

\title{
EXCHANGE RATES AND UNCOVERED INTEREST DIFFERENTIALS: THE ROLE OF PERMANENT MONETARY SHOCKS
}

\author{
Stephanie Schmitt-Grohé \\ Martín Uribe \\ Working Paper 25380 \\ http://www.nber.org/papers/w25380 \\ NATIONAL BUREAU OF ECONOMIC RESEARCH \\ 1050 Massachusetts Avenue \\ Cambridge, MA 02138 \\ December 2018, Revised November 2020
}

We thank Larry Christiano, B. Ravikumar, Gernot Müller, Juan Pablo Nicolini, Vivian Yue, Sarah Zubairy, and seminar participants at Wharton, Royal Holloway, Stockholm University, Columbia University, Michigan, Fordham, the Bank for International Settlement, the HeiTüHo Workshop on International Financial Markets, the Texas Monetary Conference, Purdue, Maryland, UC Davis, the Board of Governors, CUNY, the IJCB conference, the Konstanz Monetary Conference, the Bank of Portugal Conference of Monetary Economics, the St. Louis Fed, and Dallas Fed-UH-Banco de Mexico Conference for comments. The views expressed herein are those of the authors and do not necessarily reflect the views of the National Bureau of Economic Research.

NBER working papers are circulated for discussion and comment purposes. They have not been peer-reviewed or been subject to the review by the NBER Board of Directors that accompanies official NBER publications.

(C) 2018 by Stephanie Schmitt-Grohé and Martín Uribe. All rights reserved. Short sections of text, not to exceed two paragraphs, may be quoted without explicit permission provided that full credit, including $\odot$ notice, is given to the source. 
Exchange Rates and Uncovered Interest Di erentials: The Role of Permanent Monetary Shocks Stephanie Schmitt-Grohé and Martín Uribe

NBER Working Paper No. 25380

December 2018, Revised November 2020

JEL No. E4,F3,F40

\begin{abstract}
$\underline{\text { ABSTRACT }}$
This paper estimates an empirical model of exchange rates and uncovered interest rate differentials with permanent U.S. monetary policy shocks. Using post-Bretton-Woods data from the United States, the United Kingdom, Japan, and Canada, it reports two main findings: First, monetary shocks that increase the U.S. nominal interest rate and inflation in the long run depreciate the dollar in nominal and real terms in the short run. Second, permanent increases in the U.S. interest rate cause short-run deviations from uncovered interest-rate parity against U.S. assets. The signs of these effects are opposite to those reported in the related literature for transitory monetary policy shocks. The estimated responses to transitory and permanent monetary shocks are shown to be qualitatively consistent with the predictions of a new Keynesian model of the open economy with portfolio adjustment costs.
\end{abstract}

\author{
Stephanie Schmitt-Grohé \\ Department of Economics \\ Columbia University \\ 420 West 118th Street, MC 3308 \\ New York, NY 10027 \\ and NBER \\ stephanie.schmittgrohe@ columbia.edu \\ Martín Uribe \\ Department of Economics \\ Columbia University \\ International Affairs Building \\ New York, NY 10027 \\ and NBER \\ martin.uribe@ columbia.edu
}




\section{Introduction}

How do monetary disturbances affect exchange rates and cross-country return differentials? A defining characteristic of the vast existing literature devoted to elucidating this question is the assumption that monetary shocks come in only one type. The contribution of the present paper is to distinguish between temporary and permanent monetary shocks. Doing so reveals that the effects of these two types of shock on exchange rates and cross-country asset return differentials can be diametrically opposed.

The analysis presented in this paper is both empirical and theoretical. The empirical analysis is based on a model with few structural assumptions. The domestic country is taken to be the United States and the foreign country the United Kingdom, Japan, or Canada. The U.S. permanent monetary shock is identified by assuming that it is cointegrated with U.S. inflation and the U.S. nominal interest rate. Transitory U.S. monetary policy shocks are identified by assuming that they have a zero impact effect on U.S. inflation and U.S. output (as in Christiano, et al., 2005).

In addition to U.S. transitory and permanent monetary shocks, the empirical model features a foreign permanent monetary shock. Like in the United States, in the foreign country the nominal interest rate and inflation are assumed to be cointegrated. Unlike in the United States, however, in the foreign country the common permanent component of inflation and interest rates is a linear combination of the U.S. and foreign permanent monetary shocks. This assumption defines the U.S. central bank as a monetary authority with potentially a global impact. Its impact on each country is estimated. This specification nests as polar

cases one in which there is a single global permanent monetary shock (originating in the United States) and one in which the permanent component of inflation and nominal rates in the foreign country is independent of the U.S. permanent monetary shock. In light of the empirical evidence, the model imposes stationarity in the real depreciation rate. The model is cast in terms of latent variables, solved using the Kalman filter, and estimated using Bayesian methods on data covering the period 1974Q1 to 2018Q1. 
The paper finds that transitory increases in the U.S. nominal interest rate cause a persistent appreciation of the domestic currency, which is in line with the results of earlier studies. By contrast, monetary shocks that increase U.S. interest rates and inflation in the long run are found to cause a nominal and real depreciation of the U.S. dollar already in the short run. This suggests that information on whether movements in nominal interest rates are driven by permanent or transitory monetary shocks is key to predicting the direction in which the exchange rate will move.

The distinction between transitory and permanent monetary shocks also has important consequences for the dynamics of uncovered interest rate differentials. As in the related empirical literature, a transitory increase in the nominal interest rate causes a short-run departure from uncovered interest rate parity in favor of domestic assets. By contrast, a permanent increase in the nominal interest rate causes a departure from uncovered interest rate parity against domestic assets. This result suggests that carry-trade speculation conditional on monetary shocks may have different pay-offs than is implied by estimates that do not distinguish permanent from transitory shocks.

The estimated empirical model predicts that domestic and foreign permanent monetary shocks jointly explain a significant fraction of the forecast error variance of the nominal and real exchange rate and uncovered interest rate differentials at horizons of 1 to 4 years, while transitory monetary shocks are found to matter less, playing an insignificant role in most estimations.

A further contribution of the paper is to show that the sharp differences in the responses of exchange rates and uncovered interest rate differentials to transitory and permanent monetary shocks predicted by the estimated empirical model can be rationalized by an optimizing open economy model with nominal rigidities and financial frictions. Nominal rigidities allow for monetary shocks to have effects not only on nominal but also on real exchange rates. Financial frictions allow for equilibrium deviations from uncovered interest rate parity. In the theoretical model we consider, nominal rigidities take the form of Calvo-type price stickiness 
as in Galí and Monacelli (2005) and financial frictions take the form of portfolio adjustment costs as in Schmitt-Grohé and Uribe (2003). Yakhin (2020) shows that a model with this type of portfolio adjustment costs is, up to first order, isomorphic to models with segmentation in international asset markets as in Gabaix and Maggiori (2015), Itskhoki and Mukhin (2019), and Fanelli and Straub (2019).

The intuition for why a monetary shock that leads to an increase in the nominal interest rate in the long run depreciates the nominal exchange rate already in the short run is that it is a harbinger of higher future inflation. Being a forward looking asset price, the current exchange rate factors in these inflationary expectations as they arrive. The prediction that a rise in the policy rate is associated with a depreciation of the exchange rate in the short run represents an open economy manifestation of the neo Fisher effect. By contrast, a purely transitory monetary tightening causes an appreciation of the nominal exchange rate by the standard Dornbusch (1976) mechanism. We show, however, that the appreciation in response to a transitory monetary shock turns into a depreciation when the shock becomes sufficiently persistent.

In the theoretical model, the effects of transitory and permanent monetary policy shocks on the uncovered interest rate differential are determined by a tradeoff between intertemporal and intratemporal consumption substitution. When the intratemporal elasticity exceeds the intertemporal elasticity of consumption substitution, which is the case most commonly studied in international business cycle analysis, permanent monetary tightenings lead to uncovered interest rate differentials against the high interest rate currency and transitory tightenings move them in favor of the high interest rate currency. These effects are in line with those predicted by the empirical model. However, the theoretical model predicts the opposite when the intertemporal elasticity of consumption substitution exceeds the intratemporal one.

This paper is related to a large theoretical and empirical body of work on the effects of monetary policy shocks on exchange rates and cross-country return differentials. Monetary policy shocks have been identified in the context of international empirical models 
using a variety of methods including recursive identification (Eichenbaum and Evans, 1995), structural vector autoregression models (Kim and Roubini, 2000; Faust and Rogers, 2003; Bjørnland, 2009), sign restrictions (Scholl and Uhlig, 2008; Kim, Moon, and Velasco, 2017), high-frequency identification (Faust, Rogers, Swanson, and Wright, 2003), and the Romer and Romer narrative approach (Eichenbaum and Evans, 1995; Hettig, Müller, and Wolf, 2019). The two main conclusions that have emerged from this body of work are: First, the domestic currency appreciates in response to a tightening in domestic monetary policy. Second, a contractionary monetary shock causes a persistent deviation from uncovered interest rate parity in favor of domestic interest-bearing assets. This paper contributes to this literature by showing that the response of exchange rates and uncovered interest rate differentials to a monetary shocks depends crucially on whether the shock is transitory or permanent.

Another theme of this body of work is exchange rate overshooting. The consensus finding, with the exception of the aforementioned studies using the narrative identification approach, appears to be the presence of overshooting, namely, that in response to a contractionary monetary shock the exchange appreciates more in the short run than in the long run. The empirical analysis of the present paper, by contrast, finds that once one distinguishes between temporary and permanent monetary disturbances, exchange rate overshooting tends to disappear as the currency experiences a gradual appreciation in response to temporary tightenings and a gradual depreciation in response to permanent tightenings.

A related paper that also considers the effects of permanent monetary disturbances on the exchange rate is De Michelis and Iacoviello (2016). These authors find, consistent with the empirical results reported in the present paper, that in response to an increase in the U.S. inflation target, the U.S. real exchange temporarily depreciates. Unlike the present study, this paper does not analyze the effects of monetary policy shocks on nominal exchange rates or uncovered interest rate differentials. In addition, it does not jointly estimate the effects of temporary and permanent monetary disturbances. To the best of our knowledge the present study represents the first attempt to implement this distinction in the context of 
an international empirical and theoretical model and to document that it has significant consequences for the dynamics of exchange rates and excess returns.

More broadly, the present paper is also related to papers on foreign exchange risk premia. Engel (2016) estimates a vector error correction system in the nominal exchange rate, the cross country price-level differential, and the nominal interest-rate differential and extracts the permanent component of the nominal exchange rate. Hassan and Mano (2019) find that correcting for uncertainty about future mean interest rates yields that the hypothesis that high interest rate currencies are expected to depreciate cannot be rejected. Mueller, Tahbaz-Salehi, and Vedolin (2017) document that daily returns on currency portfolios increase on FOMC announcement days. Zhang (2020) and Wiriadinata (2020), respectively, document that the shares of dollar-invoiced imports and dollar-denominated external debt are significant determinants of spillovers of U.S. monetary shocks on exchange rates.

The theoretical model developed in this paper extends the work of Galí and Monacelli (2005), Itskhoki and Mukhin (2019), and Yakhin (2020) to an environment with permanent monetary disturbances. Finally, the empirical framework employed in this paper is an open-economy extension of the latent-variable empirical model of permanent and temporary monetary shocks introduced by Uribe (2018).

The remainder of the paper is organized as follows. Section 2 characterizes theoretically the effects of temporary and permanent monetary shocks in a new-Keynesian open economy model with deviations from uncovered interest rate parity. Section 3 presents the empirical model and the identification scheme. Section 4 explains the estimation procedure. Section 5 presents the estimated responses of exchange rates and interest rate differentials to permanent and transitory monetary shocks. Section 6 performs forecast error variance decompositions to document the importance of permanent monetary shocks as drivers of nominal and real exchange rates and uncovered interest rate differentials. Section 7 concludes. 


\section{A Model with Permanent Monetary Policy Shocks and Deviations from UIP}

The effects of transitory monetary policy shocks in new Keynesian models of the closed and open economy are well studied. This class of model predicts that transitory monetary tightenings depress output and inflation in the short run and appreciate the domestic currency. There is less work on the effects of permanent monetary policy shocks in new Keynesian models. In the context of a closed economy model, Uribe (2018) and Azevedo, Ritto, and Teles (2019) show that monetary shocks that lead to an increase in the nominal interest rate and inflation in the long run are in the short run associated with increases in interest rates, inflation and output. There is also little work on understanding the way in which transitory and permanent monetary policy shocks affect deviations from uncovered interest parity. Addressing this issue requires the introduction of some form of financial friction in international asset markets.

In this section, we investigate, in the context of a theoretical model, how permanent and transitory monetary disturbances affect nominal and real exchange rates and deviations from uncovered interest rate parity. We begin by studying an extension of the complete asset market open economy new Keynesian model of Galí and Monacelli (2005) augmented with permanent monetary shocks. We then extend this model to incorporate segmentation in international asset markets along the lines of Gabaix and Maggiori (2015), Itskhoki and Mukhin (2019), and Yakhin (2020).

\subsection{The Galí-Monacelli Model with Permanent Monetary Shocks}

In the Galí and Monacelli (2005) open economy model monetary non-neutrality is a consequence of the assumption that nominal prices of domestically produced goods (home goods) are subject to Calvo-type price setting frictions. In this framework equilibrium dynamics 
can be cast in terms of the same three equations as in a closed economy new Keynesian model, namely, an intertemporal IS curve, an expectations-augmented Phillips curve, and a Taylor rule. Here we show that in the presence of permanent monetary policy shocks, the equilibrium of the model can still be expressed in terms of these three equations with one modification in the Phillips curve. Specifically, the IS curve takes the form

$$
\hat{Y}_{H, t}=E_{t} \hat{Y}_{H, t+1}-\frac{1}{\sigma}\left[i_{t}-E_{t} \pi_{H, t+1}-\rho-r_{t}^{n}\right]
$$

where $\hat{Y}_{H, t}$ denotes log-deviations of domestic output from its non-stochastic steady state value, $1 / \sigma$ denotes the intertemporal elasticity of substitution, $i_{t}$ denotes the nominal interest rate, $\pi_{H, t}$ denotes domestic inflation, $\rho$ denotes the subjective discount rate, and $r_{t}^{n}$ denotes shocks to the natural rate of interest. Equation (1) is the same as the intertemporal IS equation in a model without permanent monetary policy shocks.

The Phillips curve can be written as

$$
\Delta \pi_{H, t}=\beta E_{t} \Delta \pi_{H, t+1}+\kappa \hat{Y}_{H, t}+\mu_{t},
$$

where $\mu_{t}$ is a combination of exogenous, non-monetary shocks. The difference between this Phillips curve and the one that arises in a version of the model without permanent monetary policy shocks is that it features the change in the inflation rate, $\Delta \pi_{H, t} \equiv \pi_{H, t}-\pi_{H, t-1}$, instead of its level, $\pi_{H, t}$. This is so because when the economy is buffeted by permanent monetary shocks, the existence of a balanced growth path for nominal variables requires some form of price indexation. That is, when a firm does not receive a price change signal, then it must be allowed to adjust its price as a function of some lagged indicator of trend inflation. To obtain the simple expression for the Phillips shown above, it is assumed that firms index to $\pi_{H, t-1}$. One can allow for alternative indexation schemes, but we find that doing so complicates the expression for the Phillips curve without changing the qualitative effects of permanent monetary policy shocks, which is the prediction of the model we are 
most interested in. ${ }^{1}$

Monetary policy is assumed to follow a Taylor rule, whereby the nominal interest rate is set as a linear function of current inflation of the domestically produced good, $\pi_{H, t}$, and the output gap, $\hat{Y}_{H, t}$. In the presence of a permanent monetary policy shock the Taylor rule becomes

$$
i_{t}=\rho+\alpha_{\pi} \pi_{H, t}+\alpha_{y} \hat{Y}_{H, t}+z_{t}^{m}+\left(1-\alpha_{\pi}\right) X_{t}^{m}
$$

where $z_{t}^{m}$ is a stationary monetary disturbance and $X_{t}^{m}$ is a nonstationary monetary disturbance, which can be interpreted as a permanent inflation target shock. The parameters $\alpha_{\pi}>1$ and $\alpha_{y}>0$ are the coefficients of the Taylor rule. In equilibrium, both the nominal interest rate and inflation are cointegrated with $X_{t}^{m}$. The monetary disturbances $z_{t}^{m}$ and $X_{t}^{m}$ are the focus of the present analysis. We assume that $z_{t}^{m}$ and $\Delta X_{t}^{m}$ follow univariate $\operatorname{AR}(1)$ processes with serial correlations $\rho_{z m}$ and $\rho_{X m}$.

The model thus consists of paths for $i_{t}, \pi_{H, t}$, and $\hat{Y}_{H, t}$ satisfying (1), (2), and (3), given exogenous processes for $z_{t}^{m}, \Delta X_{t}^{m}, r_{t}^{n}$, and $\mu_{t}$. Given equilibrium paths for $i_{t}, \pi_{H, t}$, and $\hat{Y}_{H, t}$, one can obtain the equilibrium paths of the nominal and real exchange rates. The online appendix (Schmitt-Grohé and Uribe, 2020) provides a detailed derivation of the equilibrium conditions of the model. It also shows how to cast the model in stationary variables and discusses the calibration and numerical solution method.

We characterize the predictions of the model numerically. The calibration of the structural parameters of the model follows Galí (2015, Chapter 8): $\sigma=1, \beta=0.99, \rho=-\ln \beta=$ $0.0101, \alpha_{\pi}=1.5, \alpha_{y}=0.125$, and $\kappa=0.5150$. The parameter $\kappa$ in turn is a function of the intertemporal elasticity of substitution, $1 / \sigma$, of the intratemporal elasticity of substitution between home and foreign consumption goods, $\eta$, which takes the value 1 , of the Calvo price stickiness parameter (the probability that a firm will not be allowed to reoptimize prices),

\footnotetext{
${ }^{1}$ For example, Azevedo, Ritto, and Teles (2019) assume that when firms get the chance to reoptimize prices, they pick a value for the current price level and its future growth path, which will be in effect until the next reoptimization. Uribe (2018) assumes that firms index to a weighted average of past values of trend inflation.
} 
which takes the value 0.75 , the Frisch elasticity of labor supply, which takes the value 0.2 , and the expenditure share of foreign goods in total domestic absorption, which takes the value 0.4 . The time unit is one quarter.

Figure 1 presents the impulse responses to a permanent monetary policy shock $\left(\Delta X_{t}^{m}\right)$ that increases inflation and the nominal interest rate in the long run by 1 annual percentage point together with the impulse responses to a temporary monetary policy shock $\left(z_{t}^{m}\right)$ that increases the nominal interest rate on impact by 1 annual percentage point. To highlight the endogenous dynamics of the model, $\Delta X_{t}^{m}$ and $z_{t}^{m}$ are assumed to follow i.i.d. processes $\left(\rho_{z m}=\rho_{X m}=0\right)$. The figure shows that in response to a temporary monetary policy shock the model delivers the standard dynamics. The increase in the domestic interest rate raises the real interest rate, which induces agents to save more and spend less. Faced with lower demand, firms reduce prices. Thus, in equilibrium inflation and output both fall. The domestic tightening makes the domestic currency more attractive, which results in an appreciation of the domestic currency (a fall in $S_{t}$ ). Since nominal prices are sticky, the short-run response of the real exchange rate $\left(e_{t}\right)$ mimics that of its nominal counterpart.

The dynamics are quite different after a permanent monetary policy shock. In line with the predictions of the closed economy model, the monetary authority brings about the permanent increase in the inflation target by raising interest rates in the short run. The model predicts that inflation not only increases but increases by more than the nominal rate. This is because firms who get to change their price in period 0 know that in the future prices of their competitors as well as nominal wages will grow at a faster rate. Therefore, to avoid making losses in the future by selling below costs, firms must raise prices aggressively today. Because inflation rises faster than the nominal interest rate, the real interest rate declines, which causes an expansion in aggregate demand. Since the exchange rate is a forward looking variable, it incorporates on impact the current and expected future higher cross-country inflation differential, which results in a sizeable depreciation of the nominal and real exchange rates (an increase in both $S_{t}$ and $e_{t}$ ). 
Figure 1: Impulse Responses to Permanent and Transitory Monetary Policy Shocks in the Open Economy New Keynesian Model
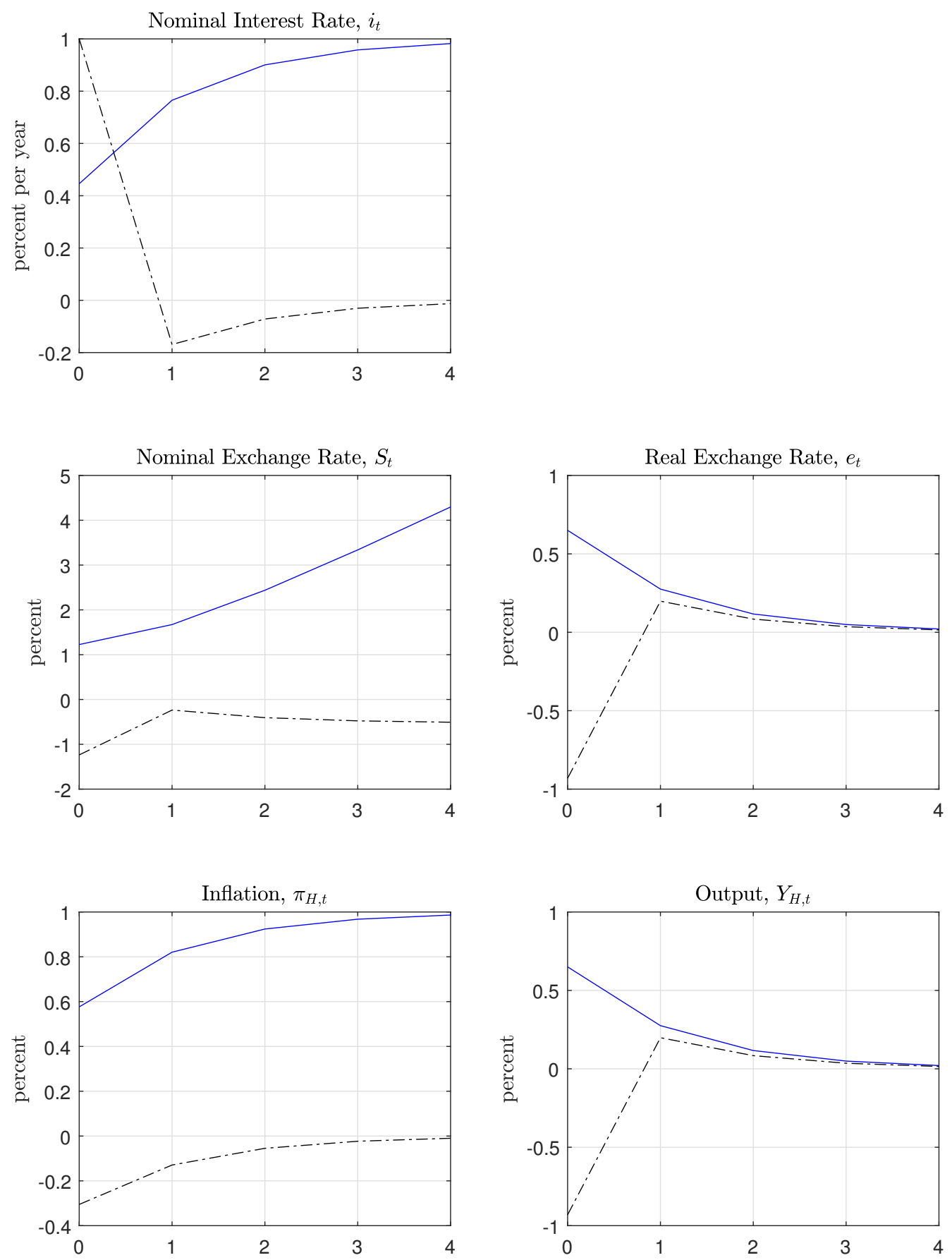

Notes. Solid lines display the impulse response to a permanent monetary shock that increases the nominal interest rate by 1 annual percentage point in the long run (an increase in $X_{t}^{m}$ ). Dashdotted lines display the impulse response to a transitory monetary shock that increases the nominal interest rate by 1 annual percentage point on impact (an increase in $z_{t}^{m}$ ). 
The prediction of the model that a transitory increase in the nominal interest rate generates an appreciation of the exchange rate is not independent of the assumed persistence of the monetary shock, $z_{t}^{m}$. In particular, under the current calibration, the nominal and real exchange rates appreciate in response to a transitory tightening if the serial correlation of the transitory monetary shock $\left(\rho_{z m}\right)$ is less than a threshold value near 0.7 , but depreciate for values greater than this threshold.

We conclude that the nominal and real exchange rates are predicted to depreciate in the short run in response to a monetary shock that increases inflation and the nominal interest

rate in the long run (an increase in $X_{t}^{m}$ ), but are predicted to either depreciate or appreciate in response to a transitory increase in the nominal interest rate (an increase in $z_{t}^{m}$ ) depending on the persistence of the transitory monetary shock. The less persistent $z_{t}^{m}$ is, the more likely it will be that the nominal and real exchange rates appreciate.

\subsection{Permanent Monetary Shocks and Deviations from Uncovered Interest Rate Parity}

The Galí-Monacelli formulation of the open economy new Keynesian model implies that up to first order, uncovered interest rate parity holds. This implication is empirically unrealistic. Furthermore, as we will see shortly, deviations from uncovered interest rate parity behave quite differently conditional on temporary and permanent monetary shocks.

The theoretical literature on how to model deviations from uncovered interest rate parity is still developing. An early contribution is Kollmann (2005), who introduces a UIP shock in the form of a disturbance to the Euler equation (i.e., the intertemporal IS curve) for foreign exchange holdings. A recent approach to microfounding the UIP shock is the work of Gabaix and Maggiori (2015), Fanelli and Straub (2019), and Itskhoki and Mukhin (2019), who introduce segmentation in the foreign exchange market. Yakhin (2020) shows that the segmented market model is isomorphic to a model with portfolio adjustment costs of the type introduced in Schmitt-Grohé and Uribe (2003). Specifically, introducing foreign 
exchange market segmentation in the present framework entails a modification of the IS curve consisting in assuming that consumption growth depends not only on the expected real rate, but also on the desired change in the economy's net foreign asset holdings.

Accordingly, we modify the new Keynesian model studied thus to allow for incomplete asset markets and portfolio adjustment costs. A detailed derivation of this version of the model is presented in the online appendix, Schmitt-Grohé and Uribe (2020). Here we present the key new features of the model, namely, the sequential budget constraint, the household's Euler equations, and the log-linear approximation of the implied uncovered interest rate differential.

Let $D_{t}$ denote domestic currency debt and $D_{t}^{*}$ foreign currency debt. Foreign debt is subject to portfolio adjustment costs, denoted $\psi\left(D_{t}^{*}\right)$, where $\psi(\cdot)$ is a convex function satisfying $\psi\left(\bar{D}^{*}\right)=\psi^{\prime}\left(\bar{D}^{*}\right)=0$ and $\bar{D}^{*}$ is a constant. Then, the household's budget constraint in equilibrium is given by

$$
P_{t} C_{t}+\left(1+i_{t-1}\right) D_{t-1}+\mathcal{E}_{t}\left(1+i_{t-1}^{*}\right) D_{t-1}^{*}=P_{H, t} Y_{H, t}+D_{t}+\mathcal{E}_{t}\left[D_{t}^{*}-\psi\left(D_{t}^{*}\right)\right]
$$

where $P_{t}$ is the price of the composite consumption good, denoted $C_{t}, i_{t}$ is the domestic nominal interest rate on debt held from period $t$ to period $t+1$, $\mathcal{E}_{t}$ denotes the domestic currency price of one unit of foreign currency, $i_{t}^{*}$ is the nominal interest rate on foreign currency debt, $P_{H, t}$ is the domestic currency price of domestically produced goods, and $Y_{H, t}$ is domestic output. The Euler equation pricing domestic currency debt is given by

$$
Z_{t} C_{t}^{-\sigma}=\beta\left(1+i_{t}\right) E_{t} Z_{t+1} C_{t+1}^{-\sigma} \frac{P_{t}}{P_{t+1}}
$$

and the Euler equation pricing foreign currency debt by

$$
Z_{t} C_{t}^{-\sigma}=\beta \frac{\left(1+i_{t}^{*}\right)}{1-\psi^{\prime}\left(D_{t}^{*}\right)} E_{t} Z_{t+1} C_{t+1}^{-\sigma} \frac{\mathcal{E}_{t+1}}{\mathcal{E}_{t}} \frac{P_{t}}{P_{t+1}}
$$


The variable $Z_{t}$ denotes an exogenous preference shock. Letting $\epsilon_{t} \equiv \ln \mathcal{E}_{t} / \mathcal{E}_{t-1}$ denote the logarithm of the depreciation rate of the domestic currency and $u i d_{t} \equiv i_{t}-i_{t}^{*}-E_{t} \epsilon_{t+1}$ the uncovered interest rate differential, then, up to a first-order approximation, the model implies that

$$
u i d_{t}=\psi^{\prime \prime}\left(\bar{D}^{*}\right)\left(D_{t}^{*}-\bar{D}^{*}\right) .
$$

According to this expression any shock that causes movements in the country's net foreign asset position will also cause deviations from uncovered interest rate parity. Intuitively, an increase in foreign debt increases marginal portfolio adjustment costs, which are factored in the cost of international borrowing faced by domestic agents. In the special case of a flat marginal portfolio adjustment cost, $\psi^{\prime \prime}\left(\bar{D}^{*}\right)=0$, uncovered interest rate parity obtains.

The calibration of this version of the model is the same as the one described in section 2.1 except for the intratemporal elasticity of substitution between home and foreign goods, $\eta$, which is now assumed to be 1.5 instead of 1 . The reason for this change is that, as is well known, when this elasticity is equal to unity and equal to the intertemporal elasticity of substitution, $1 / \sigma$, then the model displays no variations in its external accounts. The value assigned to $\eta$ lies in the range of values commonly used in trade and international business cycle analysis (e.g., Whalley, 1985; and Backus et al., 1995). The value assigned to the portfolio adjustment cost parameter, $\psi^{\prime \prime}\left(\bar{D}^{*}\right)$, is set to 1 for illustrative purposes.

Figure 2 displays impulse responses to permanent and transitory monetary shocks in the model with portfolio adjustment costs. The impulse responses of the nominal and real exchange rate are qualitatively the same as in the version of the model without portfolio adjustment costs. The model predicts that the uncovered interest rate differential responds differently to permanent $\left(X_{t}^{m}\right)$ and transitory $\left(z_{t}^{m}\right)$ monetary policy shocks.

In response to a transitory monetary shock that increases the nominal interest rate by 1 annual percentage point on impact, deviations from uncovered interest rate parity become positive, so that the high interest-rate currency exhibits excess returns. The intuition behind this result is as follows. In this model, there are two opposing effects of an increase in the 
Figure 2: Impulse Responses to a Permanent and a Transitory Monetary Policy Shock in the Open Economy New Keynesian Model with Portfolio Adjustment Costs
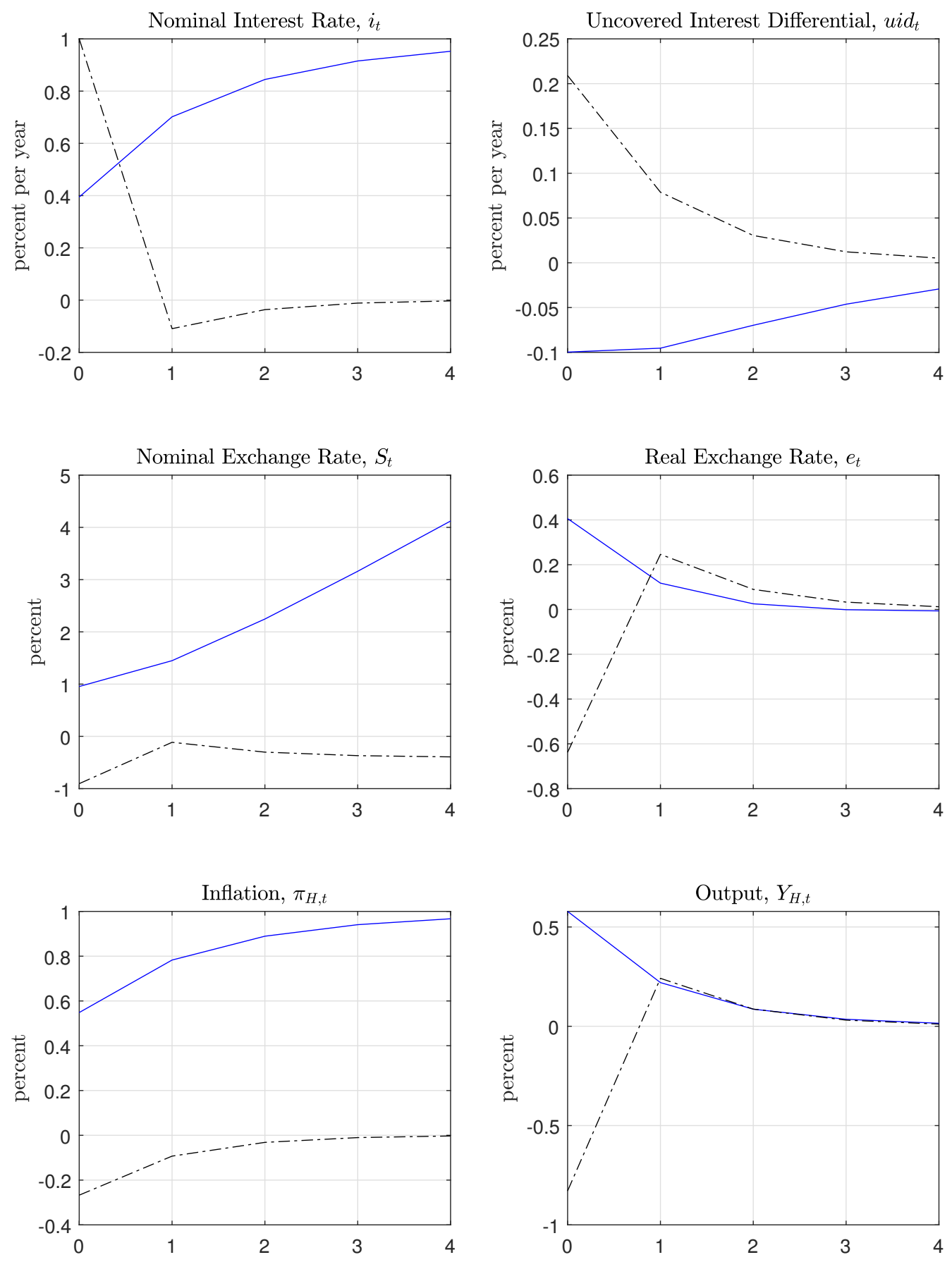

Notes. Solid lines display the impulse response to a permanent monetary shock that increases the nominal interest rate by 1 annual percentage point in the long run (an increase in $X_{t}^{m}$ ). Dashdotted lines display the impulse response to a transitory monetary shock that increases the nominal interest rate by 1 annual percentage point on impact (an increase in $z_{t}^{m}$ ). 
interest rate on the net foreign asset position, $D_{t}^{*}$, which, as shown in equation (6), determines the response of $u i d_{t}$. One is an intertemporal effect whereby the increase in $i_{t}$ raises the real interest rate, $i_{t}-E_{t} \pi_{t+1}$, because domestic prices are sticky. In turn the increase in the real interest rate encourages savings and a reduction in the country's net debt position, $D_{t}^{*}$. The strength of the intertemporal effect depends on the size of the intertemporal elasticity of substitution, $1 / \sigma$. The intertemporal effect competes with an intratemporal effect, whereby the appreciation of the exchange rate induced by the interest rate hike, worsens the country's terms of trade, deteriorates the trade balance, increases the net foreign debt position, and therefore raises $u i d_{t}$. The strength of the intratemporal effect depends on the intratemporal trade elasticity $\eta$. Thus, the sign of the response of $u i d_{t}$ to a temporary monetary tightening depends on the relative sizes of the intra- and intertemporal elasticities of substitution. Under the present calibration the intratemporal channel dominates.

By contrast, the model predicts that a permanent monetary shock that increases the nominal interest rate by 1 annual percentage point in the long run causes a fall in $u i d_{t}$, so that the high interest rate currency exhibits negative excess returns. The intuition behind this result is similar to that given above for the temporary monetary shock. As explained earlier, when the increase in the interest rate is driven by a permanent monetary policy shock, the real interest rate falls and the domestic currency depreciates. These two effects have the opposite sign to those triggered by a temporary monetary tightening and as a result also generate the opposite effect on $u i d_{t}$. It follows from this intuition that the response of uid $_{t}$ depends critically on the value of the intratemporal elasticity of substitution, $\eta$. It can be shown that setting $\eta$ below one, holding all other parameters constant, causes the responses of $u i d_{t}$ to temporary and permanent monetary shocks to change signs.

The exposition in this section serves as a theoretical framework for interpreting the results of the empirical investigation conducted in the remainder of the paper. 


\section{The Empirical Model}

The empirical model adapts the closed-economy model of temporary and permanent monetary shocks developed in Uribe (2018) to include a foreign bloc. This formulation allows for the presence of more structural shocks than observable time series, as in DSGE models, and more flexible identification restrictions than SVAR models. Here we present a self-contained description of the resulting empirical model. The model is cast in six variables: the logarithm of real domestic output, denoted $y_{t}$, domestic inflation, denoted $\pi_{t}$, the domestic nominal interest rate, denoted $i_{t}$, the foreign interest rate, denoted $i_{t}^{*}$, the foreign inflation rate, denoted $\pi_{t}^{*}$, and the depreciation rate of the domestic currency, denoted $\epsilon_{t} \equiv \ln \left(S_{t} / S_{t-1}\right)$, where $S_{t}$ denotes the spot nominal exchange rate, defined as the price of one unit of foreign currency in terms of units of domestic currency in period $t$. The variables $\pi_{t}, i_{t}, \pi_{t}^{*}, i_{t}^{*}$, and $\epsilon_{t}$ are expressed in percent per year. The domestic economy is meant to be the United States, and the foreign economy either the United Kingdom or Japan.

All six variables are assumed to be nonstationary: $y_{t}$ is assumed to be cointegrated with the exogenous variable $X_{t}$, which can be interpreted as a stochastic output trend; $i_{t}$ and $\pi_{t}$ are assumed to be cointegrated with the exogenous variable $X_{t}^{m}$, which is the permanent domestic monetary policy shock; $i_{t}^{*}$ and $\pi_{t}^{*}$ are assumed to be cointegrated with $\alpha X_{t}^{m}+X_{t}^{m *}$, where $X_{t}^{m *}$ is an exogenous variable capturing the foreign permanent monetary policy shock and $\alpha$ is a parameter to be estimated. This formulation allows the domestic and foreign interest rates and inflation rates to share a permanent component. Since both $\alpha$ and the parameters governing the stochastic process for $X_{t}^{m *}$ are estimated, two polar cases are nested: $\alpha=0$, in which inflation and interest rates have different permanent components across countries, and $\operatorname{var}\left(X_{t}^{m *}\right)=0$, in which these variables have the same permanent component. Finally, $\epsilon_{t}$ is assumed to be cointegrated with $(1-\alpha) X_{t}^{m}-X_{t}^{m *}$. This assumption implies that the real depreciation rate, $\epsilon_{t}+\pi_{t}^{*}-\pi_{t}$, is stationary. In the special case $\alpha=1$ and $\operatorname{var}\left(X_{t}^{m *}\right)=0$, the nominal depreciation rate, $\epsilon_{t}$, is also stationary. 
One can then define the following vector of stationary variables

$$
\left[\begin{array}{c}
\hat{y}_{t} \\
\hat{\pi}_{t} \\
\hat{i}_{t} \\
\hat{\epsilon}_{t} \\
\hat{i}_{t}^{*} \\
\hat{\pi}_{t}^{*}
\end{array}\right] \equiv\left[\begin{array}{c}
y_{t}-X_{t} \\
\pi_{t}-X_{t}^{m} \\
i_{t}-X_{t}^{m} \\
\epsilon_{t}-(1-\alpha) X_{t}^{m}+X_{t}^{m^{*}} \\
i_{t}^{*}-\alpha X_{t}^{m}-X_{t}^{m^{*}} \\
\pi_{t}^{*}-\alpha X_{t}^{m}-X_{t}^{m^{*}}
\end{array}\right] .
$$

This vector is assumed to evolve according to the following autoregressive process: ${ }^{2}$

$$
\left[\begin{array}{c}
\widehat{y}_{t} \\
\widehat{\pi}_{t} \\
\widehat{i}_{t} \\
\widehat{\epsilon}_{t} \\
\widehat{i}_{t}^{*} \\
\widehat{\pi}_{t}^{*}
\end{array}\right]=\sum_{i=1}^{L} B_{i}\left[\begin{array}{c}
\widehat{y}_{t-i} \\
\widehat{\pi}_{t-i} \\
\widehat{i}_{t-i} \\
\widehat{\epsilon}_{t-i} \\
\widehat{i}_{t-i}^{*} \\
\widehat{\pi}_{t-i}^{*}
\end{array}\right]+C\left[\begin{array}{c}
\Delta X_{t}^{m} \\
z_{t}^{m} \\
\Delta X_{t} \\
z_{t} \\
\Delta X_{t}^{m *} \\
z_{t}^{*} \\
w_{t}^{*}
\end{array}\right],
$$

where the exogenous variable $z_{t}^{m}$ is a stationary domestic monetary shock, and the exogenous variable $z_{t}$ is interpreted as a combination of nonmonetary stationary shocks affecting the variables in the system, which we do not wish to identify individually. The exogenous variables $z_{t}^{*}$ and $w_{t}^{*}$ are interpreted as foreign stationary shocks. These interpretations will become clear in section 3.1 below, which discusses the identification scheme. The objects $B_{i}$ for $i=1, \ldots, L$ and $C$ are matrices of coefficients, and $L$ denotes the number of lags. The

\footnotetext{
${ }^{2}$ The exposition of the model omits intercepts.
} 
driving forces are assumed to follow univariate $\mathrm{AR}(1)$ processes of the form

$$
\left[\begin{array}{c}
\Delta X_{t+1}^{m} \\
z_{t+1}^{m} \\
\Delta X_{t+1} \\
z_{t+1} \\
\Delta X_{t+1}^{m *} \\
z_{t+1}^{*} \\
w_{t+1}^{*}
\end{array}\right]=\rho\left[\begin{array}{c}
\Delta X_{t}^{m} \\
z_{t}^{m} \\
\Delta X_{t} \\
z_{t} \\
\Delta X_{t}^{m *} \\
z_{t}^{*} \\
w_{t}^{*}
\end{array}\right]+\psi\left[\begin{array}{c}
\nu_{t+1}^{1} \\
\nu_{t+1}^{2} \\
\nu_{t+1}^{3} \\
\nu_{t+1}^{4} \\
\nu_{t+1}^{5} \\
\nu_{t+1}^{6} \\
\nu_{t+1}^{7}
\end{array}\right],
$$

where $\nu_{t}^{i} \sim$ i.i.d. $\mathcal{N}(0,1)$ for $i=1, \ldots, 7$ and $\rho$ and $\psi$ are diagonal matrices.

The system consisting of equations (7) and (8) is unobservable, because neither the detrended endogenous variables nor the driving forces are observed. Thus, one can think of that system as describing the evolution of latent state variables in a state-space representation. The estimation strategy exploits the fact that the above system of latent variables has precise predictions for variables that are observable. Formally, the estimation procedure adds equations linking the unobservable variables to variables with an empirical counterpart. The included observable variables are the growth rate of real output, $\Delta y_{t}$, the domestic interestrate inflation differential, $r_{t} \equiv i_{t}-\pi_{t}$, the changes in the domestic and foreign nominal interest rates, $\Delta i_{t}$ and $\Delta i_{t}^{*}$, the change in the nominal depreciation rate, $\Delta \epsilon_{t}$, and the real depreciation rate, denoted $\epsilon_{t}^{r} \equiv \epsilon_{t}+\pi_{t}^{*}-\pi_{t}$. These variables are linked to the unobservable 
variables by the following identities:

$$
\begin{aligned}
\Delta y_{t} & =\hat{y}_{t}-\hat{y}_{t-1}+\Delta X_{t} \\
r_{t} & =\hat{i}_{t}-\hat{\pi}_{t} \\
\Delta i_{t} & =\hat{i}_{t}-\hat{i}_{t-1}+\Delta X_{t}^{m}, \\
\Delta \epsilon_{t} & =\hat{\epsilon}_{t}-\hat{\epsilon}_{t-1}+(1-\alpha) \Delta X_{t}^{m}-\Delta X_{t}^{m *}, \\
\Delta i_{t}^{*} & =\hat{i}_{t}^{*}-\hat{i}_{t-1}^{*}+\Delta X_{t}^{m *}+\alpha \Delta X_{t}^{m}, \\
\epsilon_{t}^{r} & =\hat{\epsilon}_{t}+\hat{\pi}_{t}^{*}-\hat{\pi}_{t} .
\end{aligned}
$$

The first identity says that output growth is the sum of the growth rate of detrended output and the growth rate of the output trend. The second identity says that the interest rateinflation differential equals the difference between the cyclical components of the interest rate and inflation. This is so because these two variables are assumed to have a common permanent component. Note that $r_{t}$ does not represent the real interest rate because it measures the difference between the nominal interest rate and current inflation rather than expected future inflation. The remaining identities have similar interpretations.

As is customary in Bayesian estimation, the variables on the left-hand sides of the above expressions are assumed to be observed with measurement error. Specifically, it is assumed that the econometrician observes the vector $o_{t}$ defined as

$$
o_{t}=\left[\begin{array}{c}
\Delta y_{t} \\
r_{t} \\
\Delta i_{t} \\
\Delta \epsilon_{t} \\
\Delta i_{t}^{*} \\
\epsilon_{t}^{r}
\end{array}\right]+\mu_{t},
$$

where $\mu_{t}$ is a vector of measurement errors distributed i.i.d. $\mathcal{N}(\emptyset, R)$, and $R$ is a diagonal 
variance-covariance matrix. The vector of measurement errors $\mu_{t}$ is restricted to explain no more than 10 percent of the variance of the observables.

\subsection{Identification}

The objective of the present investigation is to understand the effects of permanent and temporary U.S. monetary policy shocks $\left(X_{t}^{m}\right.$ and $\left.z_{t}^{m}\right)$ on nominal and real dollar exchange rates and uncovered interest rate differentials. The assumed formulation of the model introduces restrictions that allow for the identification of the permanent sources of uncertainty. Specifically, the assumptions that $y_{t}$ is cointegrated with $X_{t}$, that $i_{t}$ and $\pi_{t}$ are cointegrated with $X_{t}^{m}$, that $i_{t}^{*}$ and $\pi_{t}^{*}$ are cointegrated with $X_{t}^{m *}+\alpha X_{t}^{m}$, and that $\epsilon_{t}$ is cointegrated with $(1-\alpha) X_{t}^{m}-X_{t}^{m *}$, allow for the identification of the three permanent shocks. We introduce additional restrictions that allow us to identify the transitory U.S. monetary shocks following the approach of Eichenbaum and Evans (1995). Specifically, we assume that the two U.S. monetary shocks, $X_{t}^{m}$ and $z_{t}^{m}$, have zero impact effects on output and inflation. Transitory U.S. monetary shocks have a zero impact effect on output and inflation provided that

$$
C_{12}=C_{22}=C_{62}=0
$$

where $C_{i j}$ denotes element $(i, j)$ of the matrix $C$ that appears in equation $(7)$.

The permanent U.S. monetary shock, $X_{t}^{m}$, has a zero impact effect on output and domestic and foreign inflation if, respectively,

$$
C_{11}=0, C_{21}=-1 \text {, and } C_{61}=-\alpha \text {. }
$$

To see why the second restriction is required for $X_{t}^{m}$ to have a zero impact effect on $\pi_{t}$, note that element $C_{21}$ determines the impact effect of an innovation in $\Delta X_{t}^{m}$ on $\hat{\pi}_{t} \equiv \pi_{t}-X_{t}^{m}$. To see why the third restriction guarantees that the impact effect of $X_{t}^{m}$ on $\pi_{t}^{*}$ is nil, note that $C_{61}$ determines the impact effect on $\hat{\pi}_{t}^{*} \equiv \pi_{t}^{*}-X_{t}^{m *}-\alpha X_{t}^{m}$. 
Similarly, the foreign permanent monetary shock, $X_{t}^{m *}$, is assumed to have a zero impact effect on output and inflation. This requires that

$$
C_{15}=C_{25}=0, \text { and } C_{65}=-1
$$

In addition, we assume that $X_{t}^{m *}$ does not affect U.S. interest rates on impact, that is,

$$
C_{35}=0
$$

In line with the discussion in Faust and Rogers (2003), we leave unconstrained the contemporaneous response of the foreign interest rate to U.S. monetary policy, $C_{51}$ and $C_{52}$, thus allowing the foreign monetary authority to respond within the period to U.S. monetary policy shocks. The UIP shock, $w_{t}^{*}$, is assumed to affect on impact only the depreciation rate, $\epsilon_{t}$, thus, we set

$$
C_{17}=C_{27}=C_{37}=C_{57}=C_{67}=0
$$

The shock $z_{t}^{*}$ represents a second foreign stationary shock distinct from $w_{t}^{*}$ by the fact that it is allowed to affect contemporaneously not only the exchange rate but also the foreign interest rate, $i_{t}^{*}$. Accordingly, we impose

$$
C_{16}=C_{26}=C_{36}=C_{66}=0 .
$$

Without loss of generality, we normalize the impact effect of a unit innovation in the transitory U.S. monetary shock, $z_{t}^{m}$, on the U.S. nominal interest rate to unity. Similarly, we normalize to unity the impact effect of a unit innovation in the foreign transitory shock, $z_{t}^{*}$, on the foreign interest rate, $i_{t}^{*}$, the impact effect of the transitory shock, $z_{t}$, on U.S. output, $y_{t}$, and the impact effect of the UIP shock, $w_{t}^{*}$, on the depreciation rate, $\epsilon_{t}$. We therefore set

$$
C_{32}=C_{56}=C_{14}=C_{47}=1
$$


A related issue has to do with the identifiability of the parameters of the model. We check for identifiability by applying the test proposed by Iskrev (2010). In essence the Iskrev test checks whether the derivatives of the predicted autocovariogram of the observables with respect to the vector of estimated parameters has rank equal to the length of the vector of estimated parameters. After estimating the model as described in section 4, we find that, regardless of whether the foreign country is the United Kingdom, Japan, or Canada, the derivative of the vectorized predicted autocovariogram of the vector of observables with respect to the parameters has full column rank when evaluated at the posterior mean of the Bayesian estimate. Full column rank obtains starting with the inclusion of covariances of order 0 to 6 . According to this test, therefore, for all three country pairs the parameter vector is identifiable in the neighborhood of the mean of the posterior estimate. Specifically, the test result indicates that in the neighborhood of the estimate all values of the vector of parameters different from the estimated one give rise to autocovariograms that are different from the one associated with the posterior mean estimate.

\section{Estimation}

For the purpose of estimating the model, it is convenient to express it in a first-order statespace form. To this end let

$$
\begin{aligned}
\hat{Y}_{t} & \equiv\left[\begin{array}{llllll}
\hat{y}_{t} & \hat{\pi}_{t} & \hat{i}_{t} & \hat{\epsilon}_{t} & \hat{i}_{t}^{*} & \hat{\pi}_{t}^{*}
\end{array}\right]^{\prime}, \\
u_{t} & \equiv\left[\begin{array}{lllllll}
\Delta X_{t}^{m} & z_{t}^{m} & \Delta X_{t} & z_{t} & \Delta X_{t}^{m *} & z_{t}^{*} & w_{t}^{*}
\end{array}\right]^{\prime}, \\
\nu_{t} & \equiv\left[\begin{array}{lllllll}
\nu_{t}^{1} & \nu_{t}^{2} & \nu_{t}^{3} & \nu_{t}^{4} & \nu_{t}^{5} & \nu_{t}^{6} & \nu_{t}^{7}
\end{array}\right]^{\prime},
\end{aligned}
$$

and

$$
\xi_{t} \equiv\left[\begin{array}{lllll}
\hat{Y}_{t}^{\prime} & \hat{Y}_{t-1}^{\prime} & \ldots & \hat{Y}_{t-L+1}^{\prime} & u_{t}^{\prime}
\end{array}\right]^{\prime}
$$


Table 1: Prior Distributions

\begin{tabular}{llll}
\hline \hline Parameter & Distribution & Mean. & Std. Dev. \\
\hline Main diagonal elements of $B_{1}$ & Normal & 0.95 & 0.5 \\
All other elements of $B_{i}, i=1, \ldots, L$ & Normal & 0 & 0.25 \\
$C_{31}, C_{55}$ & Normal & -1 & 1 \\
$C_{45}$ & Normal & 1 & 1 \\
$C_{41}, C_{51}$ & Uniform[-1,0] & -0.5 & 0.2887 \\
All other estimated elements of $C$ & Normal & 0 & 1 \\
$\alpha$ & Uniform $[0,1]$ & 0.5 & 0.2887 \\
$\psi_{i i}, i=1, \ldots, 7$ & Gamma & 1 & 1 \\
$\rho_{i i}, i=1,2,3,5,6,7$ & Beta & 0.3 & 0.2 \\
$\rho_{44}$ & Beta & 0.7 & 0.2 \\
$R_{i i}, i=1, \ldots, 7$ & Uniform $\left[0, \frac{\operatorname{var}\left(o_{t}\right)}{10}\right]$ & $\frac{\operatorname{var}\left(o_{t}\right)}{10 \times 2}$ & $\frac{\operatorname{var}\left(o_{t}\right)}{10 \times \sqrt{12}}$ \\
Elements of $A$ & Normal & $\operatorname{mean}\left(o_{t}\right)$ & $\sqrt{\frac{\operatorname{var}\left(o_{t}\right)}{T}}$ \\
\hline \hline
\end{tabular}

Notes. $T$ denotes the sample length. The vector $A$ denotes the mean of the vector $o_{t}$, and is defined in Appendix A.

Then the system (7)-(10) can be written as

$$
\xi_{t+1}=F \xi_{t}+P \nu_{t+1},
$$

and

$$
o_{t}=H^{\prime} \xi_{t}+\mu_{t},
$$

where the matrices $F, P$, and $H$ are known functions of the matrices $B_{i}$ for $i=1, \ldots, L$, $C, \rho$, and $\psi$ and are shown in Appendix A. This representation allows for the use of the Kalman filter to calculate the likelihood of the data $\left\{o_{1} o_{2} \ldots o_{T}\right\}$, where $T$ is the number of observations. The model is estimated using Bayesian techniques. The specification includes 4 lags in equation (7), $L=4$.

\subsection{Priors}

Table 1 describes the assumed prior distributions of the estimated parameters. Normal prior 
distributions are imposed on all elements of $B_{i}$, for $i=1, \ldots, L$. In the spirit of the Minnesota prior, it is assume that at the mean of the prior parameter distribution the elements of $\hat{Y}_{t}$ follow univariate autoregressive processes. So when evaluated at their prior mean, only the main diagonal of $B_{1}$ takes nonzero values and all other elements of $B_{i}$ for $i=1, \ldots, L$ are nil. An autoregressive coefficient of 0.95 is assumed in all equations, so that all elements along the main diagonal of $B_{1}$ take a prior mean of 0.95 . The prior standard deviation of the diagonal elements of $B_{1}$ is equal to 0.5 , which implies a coefficient of variation close to one half $(0.5 / 0.95)$. Lower prior standard deviations of 0.25 are imposed on all other elements of the matrices $B_{i}$ for $i=1, \ldots, L$.

All estimated elements of the matrix $C$ are assumed to have normal prior distributions with mean zero and unit standard deviation, with the following exceptions: First, element $C_{31}$, which governs the response of $\hat{i}_{t} \equiv i_{t}-X_{t}^{m}$ to an innovation in $\Delta X_{t}^{m}$, is assumed to have a prior mean of -1 . This means that a shock that increases the U.S. nominal rate in the long run by 1 percentage point, under the prior, has a zero impact effect on the nominal interest rate. Second, $C_{55}$ is assumed to have a prior mean of -1 . This implies that a foreign permanent monetary shock that increases the foreign nominal interest rate in the long run by 1 percentage point has a prior mean impact effect on the foreign nominal interest rate of zero. Third, $C_{45}$, which governs the response of $\hat{\epsilon}_{t} \equiv \epsilon_{t}-(1-\alpha) X_{t}^{m}+X_{t}^{m *}$ to an innovation in $\Delta X_{t}^{m *}$ is assumed to have a prior mean of 1 . This implies that a foreign monetary shock that increases the foreign interest rate in the long run by 1 percentage point has a zero impact effect on the nominal exchange rate under the prior. Fourth, the prior means of $C_{41}$ and $C_{51}$, which govern the response of $\hat{\epsilon}_{t} \equiv \epsilon_{t}-(1-\alpha) X_{t}^{m}+X_{t}^{m *}$ and $\hat{i}_{t}^{*} \equiv i_{t}^{*}-\alpha X_{t}^{m}-X_{t}^{m *}$ to an innovation in $\Delta X_{t}^{m}$, are assumed to be equal to $-(1-\alpha)$ and $-\alpha$, respectively. This implies that under the prior, the impact effects on the depreciation rate, $\epsilon_{t}$, and the foreign nominal interest rate, $i_{t}^{*}$, in response to a permanent U.S. monetary policy shock, $X_{t}^{m}$, that increases the U.S. interest rate in the long run by 1 percentage point, are both 0 . Furthermore, the cointegration parameter $\alpha$ is assumed to have a uniform prior 
distribution over the interval $[0,1]$. The parameters $\psi_{i i}$, for $i=1, \ldots, 7$, representing the standard deviations of the seven exogenous innovations in the $\operatorname{AR}(1)$ process (8) are all assigned Gamma prior distributions with mean and standard deviation equal to one. The serial correlations of the exogenous shocks $\left(\rho_{i i}\right.$ for $\left.i=1, \ldots, 7\right)$ are restricted to be positive and to have Beta prior distributions. The prior serial correlations of all disturbances other than $z_{t}$ are assumed to have a relatively small mean of 0.3 . The prior serial correlation of the stationary nonmonetary shock $\left(z_{t}\right)$ is assumed to have a relatively high prior mean of 0.7 , as it is meant to represent the effects of productivity shocks and other real stationary shocks that are typically estimated to be persistent. The prior distributions of all serial correlations are assumed to have a standard deviation of 0.2 . The variances of all measurement errors, $R_{i i}$, are assumed to have a uniform prior distribution with lower bound 0 and upper bound of 10 percent of the sample variance of the corresponding observable indicator. Although not explicitly discussed thus far, the estimated model includes constants. These constants appear in the observation equation (12), for details see Appendix A. The unconditional means of the observables are assumed to have normal prior distributions with means equal to their sample means and standard deviations equal to their sample standard deviations divided by the square root of the length of the sample period.

To draw from the posterior distribution of the estimated parameters, we apply the Metropolis-Hastings sampler. We construct a Monte-Carlo Markov chain (MCMC) of two million draws and burn the initial one million draws. Posterior means and error bands around the impulse responses shown in later sections are constructed from a random subsample of the MCMC chain of length 100 thousand with replacement.

\subsection{Data}

The estimation uses quarterly data from 1974:Q1 to 2018:Q1 from the United States, the United Kingdom, Japan and Canada. Output, $y_{t}$, is measured by real GDP per capita. Inflation, $\pi_{t}$, is proxied by the growth rate of the GDP deflator. The measure of the nominal 
interest rate, $i_{t}$, depends on the country considered. For the United States it is the federal funds rate, for the United Kingdom it is the Official Bank Rate of the Bank of England, for Japan it is the call rate of the Bank of Japan, and for Canada it is the overnight rate. The nominal depreciation rate of the U.S. dollar, $\epsilon_{t} \equiv \ln S_{t}-\ln S_{t-1}$, is measured by the growth rate of the nominal exchange rate (dollar price of one unit of foreign currency). Thus, $\epsilon_{t}>0$ corresponds to a depreciation of the U.S. dollar against the foreign currency and $\epsilon_{t}<0$ to an appreciation. The dollar real depreciation rate, $\epsilon_{t}^{r}$, is computed as $\epsilon_{t}^{r}=\epsilon_{t}+\pi_{t}^{*}-\pi_{t}$, where $\pi_{t}^{*}$ indicates the inflation rate in the foreign country, which is either the United Kingdom, Japan, or Canada.

\section{Permanent Monetary Shocks, Exchange Rates, and Uncovered Interest Rate Differentials}

The central focus of this paper is to characterize the effects of permanent monetary shocks in the United States on exchange rates and uncovered interest rate differentials. Figure 3 addresses this issue through the lens of the empirical model. It presents the estimated impulse responses of variables of interest to temporary and permanent U.S. monetary shocks. In the figure, the foreign country is taken to be the United Kingdom.

A transitory increase in the U.S. nominal interest rate (a unit increase in $z_{t}^{m}$ ), shown with a dash-dotted line, leads to a decline in output and inflation in the United States. This finding is consistent with results obtained in the related empirical literature and supports the interpretation of $z_{t}^{m}$ as a transitory monetary shock. More central to the focus of this paper, the figure shows that a temporary tightening in the U.S. causes a persistent appreciation of the U.S. dollar, $S_{t}$. Again, this is a familiar and expected result. It is in line with the predictions of the New Keynesian model discussed in section 2 and with the existing empirical literature that has focused on the effects of transitory monetary disturbances on exchange rates (e.g., Eichenbaum and Evans, 1995). Intuitively, when the U.S. monetary authority 
Figure 3: Impulse Responses to Permanent and Transitory U.S. Monetary Shocks: United Kingdom
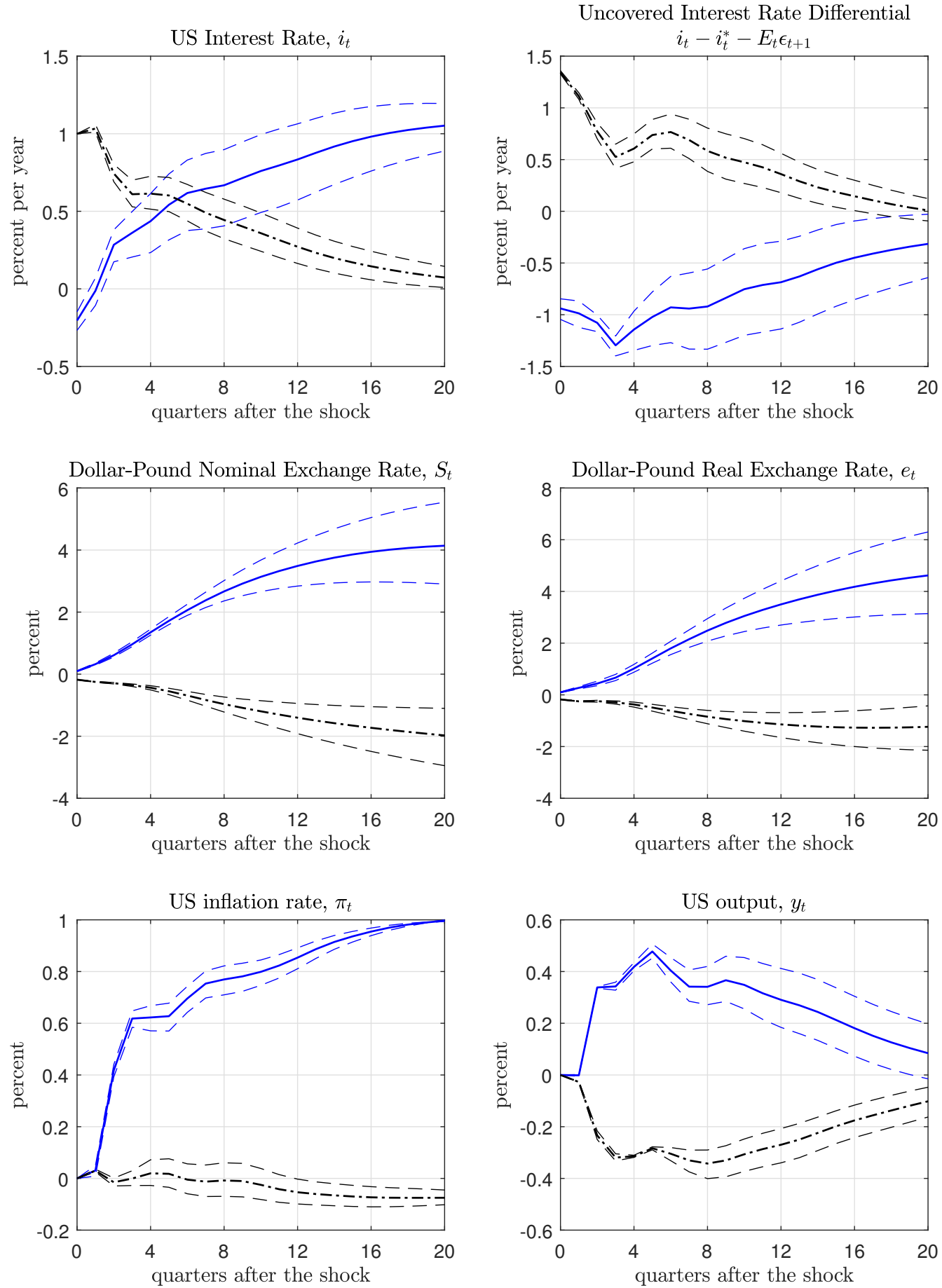

Notes. Solid lines display the posterior mean response to a permanent monetary shock that increases the U.S. nominal interest rate by 1 annual percentage point in the long run (an increase in $X_{t}^{m}$ ). Dash-dotted lines display the posterior mean response to a transitory monetary shock that increases the U.S. nominal interest rate by 1 annual percentage point on impact (an increase in $z_{t}^{m}$ ). Broken lines are asymmetric 95-percent confidence bands computed using the Sims-Zha (1999) method. 
makes the dollar more scarce, its price relative to other currencies goes up.

The responses of exchange rates and uncovered interest rate differentials are quite different when the monetary shock is of a more permanent nature. Figure 3 shows that a monetary shock that increases the U.S. nominal interest rate by one percentage point in the long run (an increase in $X_{t}^{m}$ ), shown with a solid line, produces a persistent depreciation of the U.S. dollar. Since the cointegration parameter $\alpha$ is estimated to be less than one, the increase in $X_{t}^{m}$ must depreciate the dollar in the long run. The important feature of the impulse response of $S_{t}$ to a positive innovation in $X_{t}^{m}$ is therefore the predicted depreciation of the U.S. dollar at business cycle horizons, 0 to 20 quarters.

The results obtained for the response of the nominal exchange rate extend to the real exchange rate, $e_{t} \equiv S_{t} P_{t}^{U K} / P_{t}^{U S}$. Figure 3 shows that, as in the case of the nominal exchange rate, the dollar-pound real exchange rate appreciates in response to a transitory monetary tightening but depreciates in response to a shock that increases the U.S. nominal interest rate in the long run. This finding is in line with the high correlation between the nominal and the real exchange rate observed in raw post-Bretton Woods data as stressed in the literature on the Mussa puzzle (see, for example, Mussa 1986; Kollmann, 2005; and Itskhoki and Mukhin, 2019.) Thus these results suggest that the Mussa puzzle extends to correlations conditional on identified transitory and permanent monetary shocks.

We note that neither the temporary nor the permanent monetary shock produces overshooting of the nominal or the real exchange rate, as their responses are weaker in the short run than at any point in the future. The lack of overshooting in response to temporary monetary shocks is in contrast with the existing body of empirical studies, which have found the existence of overshooting either immediately (Kim and Roubini, 2000; Faust and Rogers, 2003; Kim, Moon, and Velasco, 2017), or in a delayed fashion (Eichenbaum and Evans, 1995; Scholl and Uhlig, 2008).

Consider now the response of the uncovered interest-rate differential, $i_{t}-i_{t}^{*}-E_{t} \epsilon_{t+1}$. In line with results documented in the related empirical literature (see, for instance, the 
papers just cited), figure 3 shows that a temporary increase in the U.S. nominal interest rate causes a deviation from uncovered interest-rate parity (UIP) in favor of U.S. assets. The novel result is that, contrary to what happens under a temporary shock, a monetary shock that increases the U.S. interest rate in the long run causes a deviation from UIP against U.S. assets. This is so for two reasons. First, as we already saw, the dollar appreciates in response to a temporary monetary shock but depreciates in response to a permanent monetary shock. Second, both shocks cause an increase in the cross-country interest rate differential, $i_{t}-i_{t}^{*}$, (not shown). However, the increase in the interest rate differential is larger in response to the temporary increase in the domestic interest rate. This finding suggests that deviations from uncovered interest rate parity might give an edge to investors that have the ability to tell apart permanent from transitory monetary shocks as they take place. ${ }^{3}$

As mentioned earlier, consistent with the existing closed-economy literature on the effects of transitory monetary policy shocks, see, for example, Christiano, Eichenbaum, and Evans (2005), figure 3 shows that a temporary tightening causes a contraction in aggregate activity and a fall in inflation. By contrast, the figure shows that a permanent increase in the nominal interest rate causes an increase in inflation and an expansion in aggregate activity, in line with the findings of Uribe (2018). Thus, the neo-Fisher effect, whereby a monetary policy shock that raises the nominal interest rate in the long run causes an increase in inflation already in the short run, appears to be present not only in closed economy empirical models, but also in models that allow for a foreign bloc.

The effects of permanent U.S. monetary shocks obtained when the foreign country is taken to be the United Kingdom continue to hold when the foreign country is assumed to be either Japan or Canada. This is shown in figures 4 and 5. In particular, a monetary policy shock that increases the U.S. policy rate in the long run by one percentage point (an increase in $X_{t}^{m}$ ) causes a depreciation of the dollar vis-á-vis both the Japanese yen and the Canadian dollar already in the short run and a deviation from UIP against U.S. assets. The

\footnotetext{
${ }^{3}$ For unconditional, risk-based analyses of violations of uncovered interest rate parity see, for example, Lustig and Verdelhan (2007), Hassan (2013), and Richmond (2019).
} 
Figure 4: Impulse Responses to Permanent and Transitory U.S. Monetary Shocks: Japan
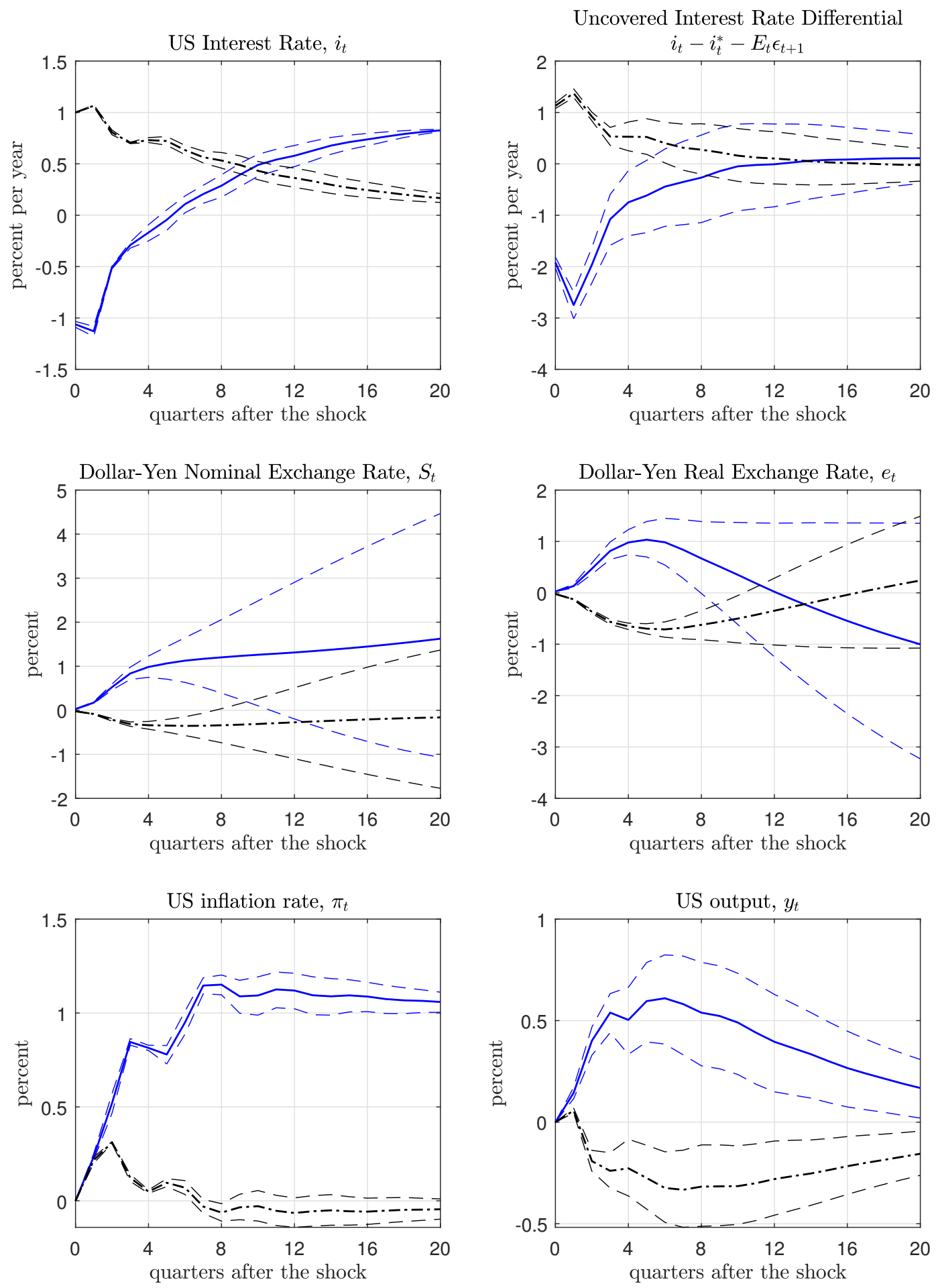

Notes. Solid lines display the posterior mean response to a permanent monetary shock that increases the U.S. nominal interest rate by 1 annual percentage point in the long run (an increase in $X_{t}^{m}$ ). Dash-dotted lines display the posterior mean response to a transitory monetary shock that increases the U.S. nominal interest rate by 1 annual percentage point on impact (an increase in $z_{t}^{m}$ ). Broken lines are asymmetric 95-percent confidence bands computed using the Sims-Zha (1999) method. 
Figure 5: Impulse Responses to Permanent and Transitory U.S. Monetary Shocks: Canada
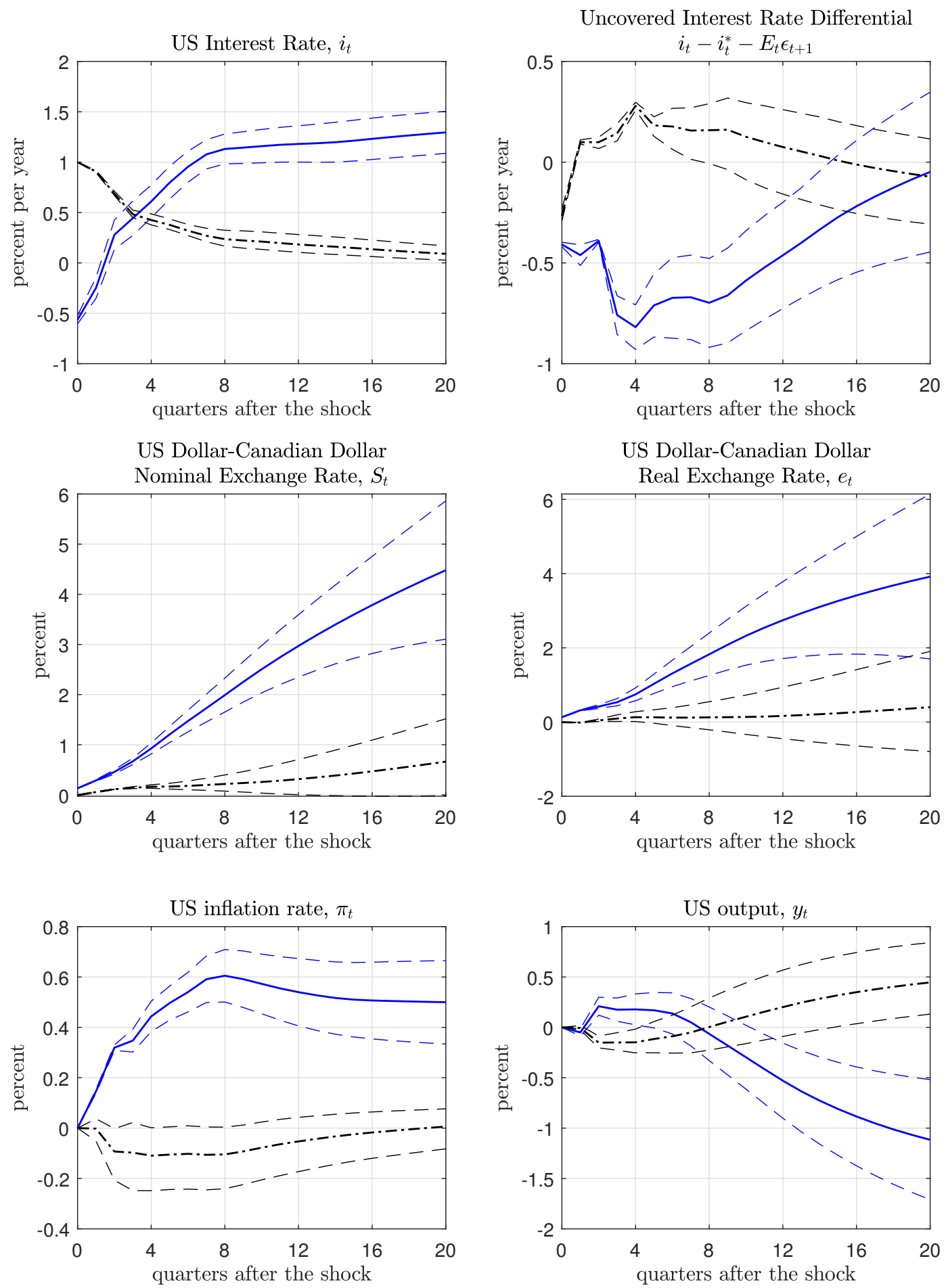

Notes. Solid lines display the posterior mean response to a permanent monetary shock that increases the U.S. nominal interest rate by 1 annual percentage point in the long run (an increase in $X_{t}^{m}$ ). Dash-dotted lines display the posterior mean response to a transitory monetary shock that increases the U.S. nominal interest rate by 1 annual percentage point on impact (an increase in $z_{t}^{m}$ ). Broken lines are asymmetric 95-percent confidence bands computed using the Sims-Zha (1999) method. 
opposite results obtain when the monetary tightening in the United States is temporary, although in the case of Canada the responses of the nominal and real exchange rates are a muted depreciation. The responses of U.S. inflation and U.S. output are also broadly in line with the results reported when the model is estimated on U.S. and U.K. data, that is, a temporary monetary tightening in the United States has the conventional contractionary effects on real activity and prices, whereas a U.S. monetary shock that increases interest rates in the long run is associated with neo-Fisherian dynamics, that is, an increase in U.S. inflation and output.

As a robustness check, the model is also estimated jointly on data from the United States, the United Kingdom, Japan, and Canada. This case is of interest because it ensures that the same permanent and transitory U.S. monetary shocks, $X_{t}^{m}$ and $z_{t}^{m}$, affect the three other countries. The results are presented in figure 6. The figure shows that a monetary shock that increases the U.S. nominal interest rate in the long run (an increase in $X_{t}^{m}$ ) causes a depreciation of the U.S. dollar vis-à-vis all other currencies in nominal and real terms already in the short run. Furthermore, an increase in $X_{t}^{m}$ leads to a deviation from uncovered interest rate parity against U.S. assets for all three currencies. Thus, the main results stressed in this paper emerge not only when the model is estimated on data from individual country pairs but also when it is estimated using data from all countries simultaneously.

It is of interest to ascertain the behavior of the permanent component of U.S. monetary policy, $X_{t}^{m}$, as viewed through the lens of the empirical model. Figure 7 displays the estimate of the permanent U.S. monetary shock, $X_{t}^{m}$ and actual U.S. inflation, $\pi_{t}$. All four estimations of the model, which use different combinations of country data, have predictions for the same object, $X_{t}^{m}$, which are plotted in the figure. The estimates of the permanent monetary component, $X_{t}^{m}$, track well low frequency movements in inflation. In particular, in all variants of the empirical model, $X_{t}^{m}$ is high during the high inflation years of the late 1970s and falls during the Volcker disinflation of the early 1980s. Also the estimates of $X_{t}^{m}$ suggest the presence of a significant permanent component in both the low inflation following the 
Figure 6: Impulse Responses to Permanent and Transitory U.S. Monetary Shocks: UKJapan-Canada
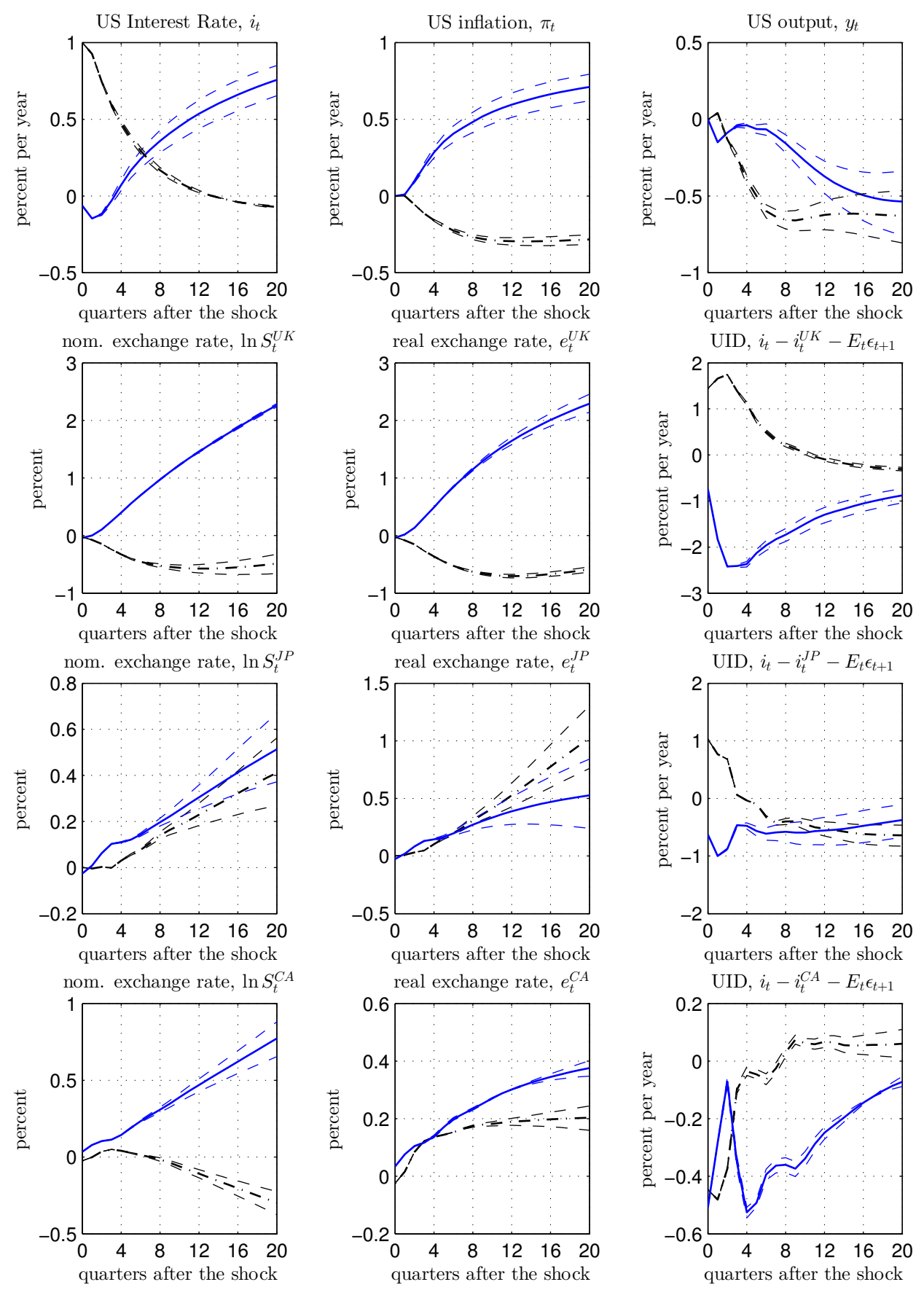

Notes. Solid lines display the posterior mean response to a permanent monetary shock that increases the U.S. nominal interest rate by 1 annual percentage point in the long run (an increase in $X_{t}^{m}$ ). Dash-dotted lines display the posterior mean response to a transitory monetary shock that increases the U.S. nominal interest rate by 1 annual percentage point on impact (an increase in $z_{t}^{m}$ ). Broken lines are asymmetric 95-percent confidence bands computed using the Sims-Zha (1999) method. 
Figure 7: U.S. Inflation and Its Permanent Component, $X_{t}^{m}$

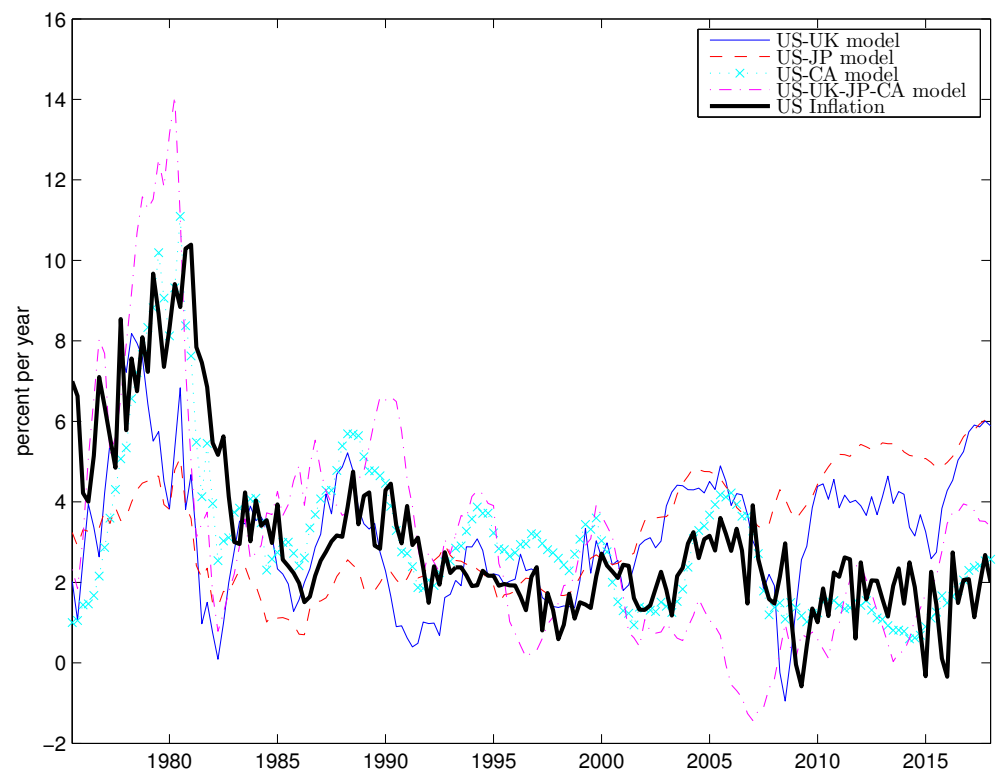

Note. For each model the permanent component of U.S. inflation, $X_{t}^{m}$, was scaled by adding a constant so that its sample mean equals the sample mean of actual U.S. inflation.

great contraction of 2008 and the increase in inflation that started when the Fed embarked on a gradual normalization of interest rates in late 2015.

\section{The Importance of Permanent Monetary Shocks for Exchange Rates and UIP: Variance Decompositions}

This section sheds light on the sources of variation in exchange rates and uncovered interest rate differentials at business cycle frequencies. Table 2 reports forecast-error variance decompositions of the nominal and real exchange rates and other variables at horizon 12 quarters, which is a standard horizon for business cycle analysis. The picture that emerges from the table is that permanent monetary shocks are important drivers of exchange rates and uncovered interest rate differentials. Jointly, the domestic and foreign permanent monetary shocks, $X_{t}^{m}$ and $X_{t}^{m *}$, explain the vast majority of the forecast-error variance of the dollar-pound 
Table 2: Forecast Error Variance Decomposition at Horizon 12 quarters

\begin{tabular}{|c|c|c|c|c|c|c|c|}
\hline & \multicolumn{7}{|c|}{ A. United Kingdom } \\
\hline & $\Delta y_{t}$ & $\pi_{t}$ & $i_{t}$ & $\ln S_{t}$ & $\ln e_{t}$ & $i_{t}^{*}$ & $i_{t}-i_{t}^{*}-E_{t} \epsilon_{t+1}$ \\
\hline Permanent Monetary Shock, $X_{t}^{m}$ & 0.29 & 0.88 & 0.47 & 0.43 & 0.39 & 0.37 & 0.14 \\
\hline Transitory Monetary Shock, $z_{t}^{m}$ & 0.05 & 0.00 & 0.27 & 0.02 & 0.02 & 0.09 & 0.03 \\
\hline Permanent Nonmonetary Shock, $X_{t}$ & 0.57 & 0.03 & 0.19 & 0.01 & 0.02 & 0.06 & 0.02 \\
\hline Transitory Nonmonetary Shock, $z_{t}$ & 0.02 & 0.00 & 0.00 & 0.00 & 0.00 & 0.02 & 0.00 \\
\hline Foreign Permanent Monetary Shock, $X_{t}^{m *}$ & 0.05 & 0.06 & 0.05 & 0.52 & 0.55 & 0.17 & 0.79 \\
\hline Foreign Transitory Shock $z_{t}^{*}$ & 0.02 & 0.03 & 0.01 & 0.02 & 0.01 & 0.29 & 0.01 \\
\hline UIP Shock, $w_{t}^{*}$ & 0.00 & 0.00 & 0.00 & 0.00 & 0.00 & 0.00 & 0.00 \\
\hline \multicolumn{8}{|c|}{ B. Japan } \\
\hline & $\Delta y_{t}$ & $\pi_{t}$ & $i_{t}$ & $\ln S_{t}$ & $\ln e_{t}$ & $i_{t}^{*}$ & $i_{t}-i_{t}^{*}-E_{t} \epsilon_{t+1}$ \\
\hline Permanent Monetary Shock, $X_{t}^{m}$ & 0.05 & 0.59 & 0.11 & 0.00 & 0.00 & 0.05 & 0.02 \\
\hline Transitory Monetary Shock, $z_{t}^{m}$ & 0.03 & 0.02 & 0.23 & 0.00 & 0.00 & 0.03 & 0.01 \\
\hline Permanent Nonmonetary Shock, $X_{t}$ & 0.23 & 0.13 & 0.01 & 0.00 & 0.00 & 0.03 & 0.01 \\
\hline Transitory Nonmonetary Shock, $z_{t}$ & 0.49 & 0.14 & 0.25 & 0.00 & 0.00 & 0.03 & 0.04 \\
\hline Foreign Permanent Monetary Shock, $X_{t}^{m *}$ & 0.13 & 0.11 & 0.35 & 0.88 & 0.87 & 0.80 & 0.76 \\
\hline Foreign Transitory Shock, $z_{t}^{*}$ & 0.00 & 0.00 & 0.00 & 0.00 & 0.00 & 0.03 & 0.00 \\
\hline UIP Shock, $w_{t}^{*}$ & 0.06 & 0.02 & 0.04 & 0.11 & 0.13 & 0.04 & 0.17 \\
\hline \multicolumn{8}{|c|}{ C. Canada } \\
\hline & $\Delta y_{t}$ & $\pi_{t}$ & $i_{t}$ & $\ln S_{t}$ & $\ln e_{t}$ & $i_{t}^{*}$ & $i_{t}-i_{t}^{*}-E_{t} \epsilon_{t+1}$ \\
\hline Permanent Monetary Shock, $X_{t}^{m}$ & 0.13 & 0.77 & 0.74 & 0.28 & 0.20 & 0.50 & 0.07 \\
\hline Transitory Monetary Shock, $z_{t}^{m}$ & 0.01 & 0.02 & 0.09 & 0.00 & 0.00 & 0.06 & 0.00 \\
\hline Permanent Nonmonetary Shock, $X_{t}$ & 0.27 & 0.11 & 0.08 & 0.65 & 0.67 & 0.09 & 0.86 \\
\hline Transitory Nonmonetary Shock, $z_{t}$ & 0.50 & 0.08 & 0.08 & 0.06 & 0.13 & 0.05 & 0.02 \\
\hline Foreign Permanent Monetary Shock, $X_{t}^{m *}$ & 0.00 & 0.00 & 0.00 & 0.00 & 0.00 & 0.01 & 0.00 \\
\hline Foreign Transitory Shock, $z_{t}^{*}$ & 0.08 & 0.02 & 0.02 & 0.00 & 0.01 & 0.28 & 0.05 \\
\hline UIP Shock, $w_{t}^{*}$ & 0.00 & 0.00 & 0.00 & 0.00 & 0.00 & 0.00 & 0.00 \\
\hline
\end{tabular}

Notes. Notation: $\Delta y_{t}$, U.S. output growth; $\pi_{t}$, U.S. inflation; $i_{t}$, the federal funds rate; $\ln S_{t}$, dollar-pound, dollar-yen, or dollar-CAD nominal exchange rate; $\ln e_{t}$, dollar-pound, dollaryen, or dollar-CAD real exchange rate; $i_{t}^{*}$, U.K., Japanese, or Canadian nominal interest rate; $\epsilon_{t}$, devaluation rate. 
and dollar-yen exchange rates and the uncovered interest rate differentials. In the case of the dollar-pound exchange rate the forecast error variance explained by permanent monetary shocks is split in roughly equal parts between the U.S. permanent monetary shock $\left(X_{t}^{m}\right)$ and the U.K. permanent monetary shock $\left(X_{t}^{m *}\right)$. In the case of the dollar-yen exchange rates virtually all of the forecast error variance is explained by the Japanese permanent monetary shock. By contrast, the U.S. transitory monetary shock $\left(z_{t}^{m}\right)$ plays a minor role in accounting for movements in exchange rates and uncovered interest rate differentials in the United Kingdom and Japan, with a forecast error variance share of less than five percent. For Canada permanent monetary shocks are relevant but not as prominent in explaining the forecast error variances of exchange rates and uncovered interest rate differentials. However, permanent monetary shocks continue to be the dominant source of monetary disturbance, as $z_{t}^{m}$ is estimated to account for a negligible fraction of the variance of exchange rates and uncovered interest rate differentials.

Table 2 further shows that for a given country the nominal and real exchange rates are driven by the same shocks. This is the case for all three currencies considered. This finding is another reflection of the Mussa fact, namely, the presence of a high degree of comovement of nominal and real exchange rates post Bretton Woods at business cycle frequencies.

Independently of whether the foreign bloc is taken to be the United Kingdom, Japan, or Canada, the U.S. permanent monetary shock is estimated to be an important driver of U.S. inflation accounting for 88, 59, and 77 percent of its forecast-error variance, respectively. This finding is similar to that obtained in Uribe (2018) in the context of closed-economy empirical and optimizing models estimated on U.S. data.

The U.S. transitory monetary shock, $z_{t}^{m}$, plays a much smaller role than the permanent monetary shock, $X_{t}^{m}$, in accounting for short-run movements in all variables with the exception of the federal funds rate when the foreign bloc is Japan. This result is of interest in light of the fact that the related literature is often aimed at understanding the importance of transitory monetary shocks. 
The result that permanent monetary shocks play an important role in explaining the forecast error variance of the nominal exchange rate, the real exchange rate, and uncovered interest rate differentials continues to hold in the U.K. and Japan at other horizons relevant for business-cycle analysis. Figure B.1 in appendix B shows forecast error variance decompositions for horizons between 1 and 16 quarters. As expected, permanent monetary shocks continue to be important at horizons longer than 12 quarters. The noteworthy result is that even at a horizon as short as 1 quarter, permanent monetary shocks explain a large fraction of the forecast-error variance of the three variables in the United Kingdom and Japan. In the case of Canada, the role of permanent monetary policy shocks falls markedly as the forecasting horizons shortens below four quarters.

To place these results in the context of the related literature, we note that a key difference with the papers cited in the introduction, for example, Eichenbaum and Evans (1995), is the distinction made here between transitory and permanent monetary disturbances. The variance decompositions reveal that permanent monetary shocks, both domestic and foreign, which are the novel source of monetary uncertainty introduced in this paper, are important. These findings suggest that if the permanent components of domestic and foreign monetary policy were to display more stability, exchange rate volatility could be greatly reduced.

\section{Conclusion}

Existing empirical studies have documented that a monetary shock that increases the domestic interest rate causes an appreciation of the domestic currency in nominal and real terms and a persistent deviation from uncovered interest parity in favor of the high-interest-rate currency. In this paper, we estimate an empirical model of exchange rates that allows for permanent and transitory monetary shocks. Using quarterly data from the United States, the United Kingdom, Japan, and Canada for the post Bretton-Woods period, we obtain the following three results. First, in the short run permanent monetary policy shocks depreci- 
ate the domestic currency whereas temporary ones appreciate it. Second, both transitory and permanent increases in the domestic nominal interest rate cause deviations from uncovered interest-rate parity but of opposite signs, the former in favor of the high interest rate currency and the latter against. Third, permanent monetary shocks explain an important fraction of short-run movements in nominal and real exchange rate and uncovered interest rate differentials, while transitory monetary shocks play a minor role.

A theoretical contribution of the paper is to show that the estimated impulse responses to transitory and permanent monetary policy shocks can be qualitatively explained in the context of a dynamic optimizing open economy model. The two key ingredients of the model are nominal rigidities and financial frictions. The former guarantees that monetary disturbances have an effect on real exchange rates and the latter allows the model to display deviations from uncovered interest rate parity. The sign of the response of the exchange rate to monetary tightenings depends on the persistence of the monetary innovation whereas the sign of the response of the uncovered interest rate differential depends on the relative magnitudes of the inter- and intratemporal elasticities of consumption substitution.

A possible policy implication of the findings presented in this paper has to do with the real consequences of an eventual normalization of nominal interest from near zero levels, as currently observed in many countries around the world, to levels in line with historical averages. The empirical and theoretical findings suggest that such normalization need not cause an appreciation of the nominal and real exchange rates, a deflation, or a contraction in economic activity. This concern, which is often voiced by policymakers, is consistent with existing results on the real consequences of transitory adjustments in policy rates. However, a process of interest rate normalization is more akin to a permanent rise in rates than to a transitory one and, as the results of this paper suggest, it should therefore be expected to trigger quite different dynamics. 


\section{Appendix A}

In this appendix, we present the empirical model in more detail showing explicitly its associated intercepts that we had omitted earlier to simplify the exposition. Let

$$
\widehat{Y}_{t} \equiv\left[\begin{array}{c}
y_{t}-X_{t}-E\left(y_{t}-X_{t}\right) \\
\pi_{t}-X_{t}^{m}-E\left(\pi_{t}-X_{t}^{m}\right) \\
i_{t}-X_{t}^{m}-E\left(i_{t}-X_{t}^{m}\right) \\
\epsilon_{t}-(1-\alpha) X_{t}^{m}+X_{t}^{m *}-E\left(\epsilon_{t}-(1-\alpha) X_{t}^{m}+X_{t}^{m *}\right) \\
i_{t}^{*}-\alpha X_{t}^{m}-X_{t}^{m *}-E\left(i_{t}^{*}-\alpha X_{t}^{m}-X_{t}^{m *}\right) \\
\pi_{t}^{*}-\alpha X_{t}^{m}-X_{t}^{m *}-E\left(\pi_{t}^{*}-\alpha X_{t}^{m}-X_{t}^{m *}\right)
\end{array}\right] \text { and } u_{t} \equiv\left[\begin{array}{c}
\Delta X_{t}^{m}-E\left(\Delta X_{t}^{m}\right) \\
z_{t}^{m} \\
\Delta X_{t}-E\left(\Delta X_{t}\right) \\
z_{t} \\
\Delta X_{t}^{m *}-E\left(\Delta X_{t}^{m *}\right) \\
z_{t}^{*} \\
w_{t}^{*}
\end{array}\right]
$$

The vector $\widehat{Y}_{t}$ evolves over time according to

$$
\widehat{Y}_{t}=\sum_{i=1}^{L} B_{i} \widehat{Y}_{t-i}+C u_{t}
$$

and the vector $u_{t}$ according to

$$
u_{t}=\rho u_{t-1}+\psi \nu_{t}
$$

Then to obtain a first-order state space representation let the vector $\xi_{t}$ be given by

$$
\xi_{t} \equiv\left[\begin{array}{lllll}
\widehat{Y}_{t}^{\prime} & \widehat{Y}_{t-1}^{\prime} & \ldots & \widehat{Y}_{t-L+1}^{\prime} & u_{t}^{\prime}
\end{array}\right]^{\prime}
$$

With these definitions and notation in hand, the empirical model becomes

$$
\xi_{t+1}=F \xi_{t}+P \nu_{t+1}
$$


and the observation equations can be written as

$$
o_{t}=A^{\prime}+H^{\prime} \xi_{t}+\mu_{t}
$$

The relationship between the matrices $B_{i}$ for $i=1, \ldots, L, C, \rho$, and $\psi$ and the matrices $A, F, P$, and $H$ is as follows. Let $V$ denote the number of variables included in the vector $\widehat{Y}_{t}$ and $S$ the number of shocks in the vector $\nu_{t}$. In the empirical implementation of the model $V=6$ and $S=7$. Further, let

$$
B \equiv\left[B_{1} \cdots B_{L}\right]
$$

and let $I_{j}$ denote an identity matrix of order $j$ and $\emptyset_{i, j}$ a zero matrix of order $i$ by $j$. Then, for $L \geq 2$ we have

$$
F=\left[\begin{array}{cc}
B & C \rho \\
{\left[I_{V(L-1)} \emptyset_{V(L-1), V}\right]} & \emptyset_{V(L-1), S} \\
\emptyset_{S, V L} & \rho
\end{array}\right], P=\left[\begin{array}{c}
C \psi \\
\emptyset_{V(L-1), S} \\
\psi
\end{array}\right], A^{\prime}=\left[\begin{array}{c}
E\left(\Delta X_{t}\right) \\
E\left(i_{t}-\pi_{t}\right) \\
E\left(\Delta X_{t}^{m}\right) \\
(1-\alpha) E\left(\Delta X_{t}^{m}\right)-E\left(\Delta X_{t}^{m *}\right) \\
E\left(\Delta X_{t}^{m *}+\alpha \Delta X_{t}^{m}\right) \\
E\left(\epsilon_{t}+\pi_{t}^{*}-\pi_{t}\right)
\end{array}\right]
$$

and

$$
H^{\prime}=\left[\begin{array}{lll}
M_{\xi} & \emptyset_{V, V(L-2)} & M_{u}
\end{array}\right]
$$


where the matrices $M_{\xi}$ and $M_{u}$ take the form

$$
M_{\xi}=\left[\begin{array}{cccccccccccc}
1 & 0 & 0 & 0 & 0 & 0 & -1 & 0 & 0 & 0 & 0 & 0 \\
0 & -1 & 1 & 0 & 0 & 0 & 0 & 0 & 0 & 0 & 0 & 0 \\
0 & 0 & 1 & 0 & 0 & 0 & 0 & 0 & -1 & 0 & 0 & 0 \\
0 & 0 & 0 & 1 & 0 & 0 & 0 & 0 & 0 & -1 & 0 & 0 \\
0 & 0 & 0 & 0 & 1 & 0 & 0 & 0 & 0 & 0 & -1 & 0 \\
0 & -1 & 0 & 1 & 0 & 1 & 0 & 0 & 0 & 0 & 0 & 0
\end{array}\right] \text { and } M_{u}=\left[\begin{array}{ccccccc}
0 & 0 & 1 & 0 & 0 & 0 & 0 \\
0 & 0 & 0 & 0 & 0 & 0 & 0 \\
1 & 0 & 0 & 0 & 0 & 0 & 0 \\
1-\alpha & 0 & 0 & 0 & -1 & 0 & 0 \\
\alpha & 0 & 0 & 0 & 1 & 0 & 0 \\
0 & 0 & 0 & 0 & 0 & 0 & 0
\end{array}\right] .
$$




\section{Appendix B: Variance Decomposition at Forecasting Hori- zons of 1 to 16 Quarters}

Figure B.1: Forecast Error Variance Decompositions of the Nominal Exchange Rate, the Real Exchange Rate, and Uncovered Interest Rate Differentials
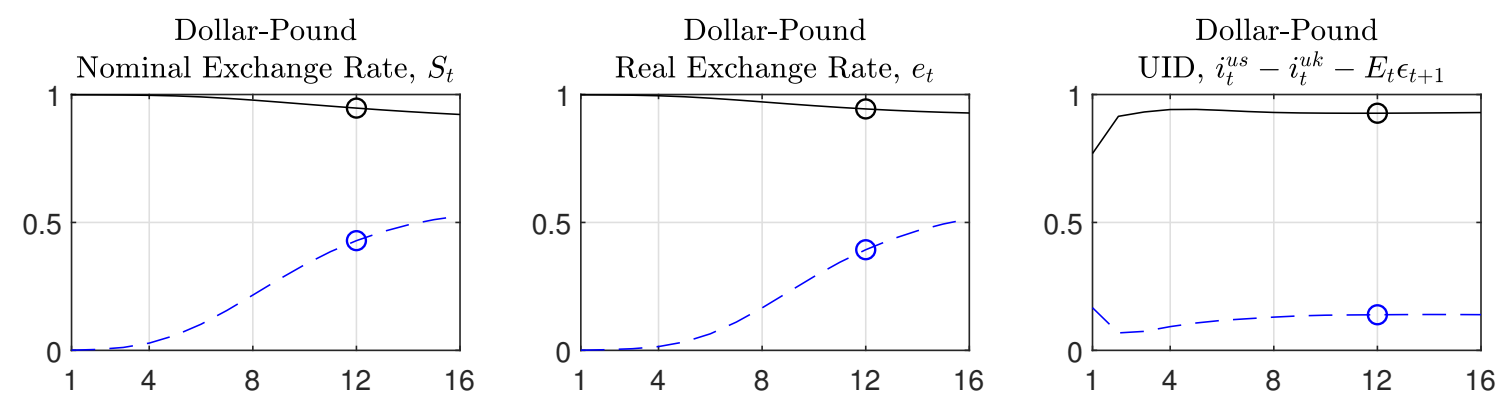

Dollar-Yen

Dollar-Yen

Dollar-Yen
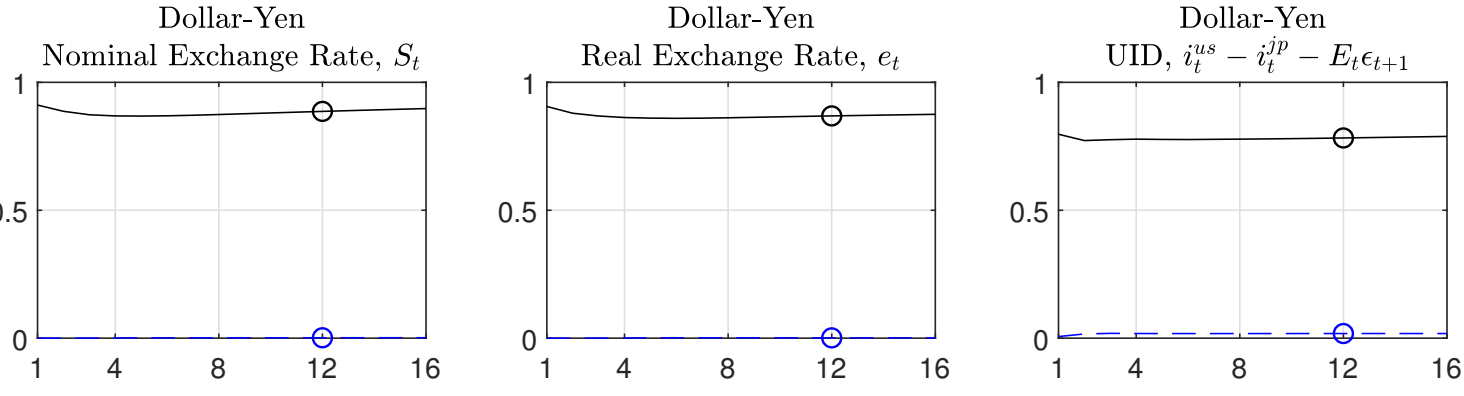

Dollar-Can Dollar

Dollar-Can Dollar
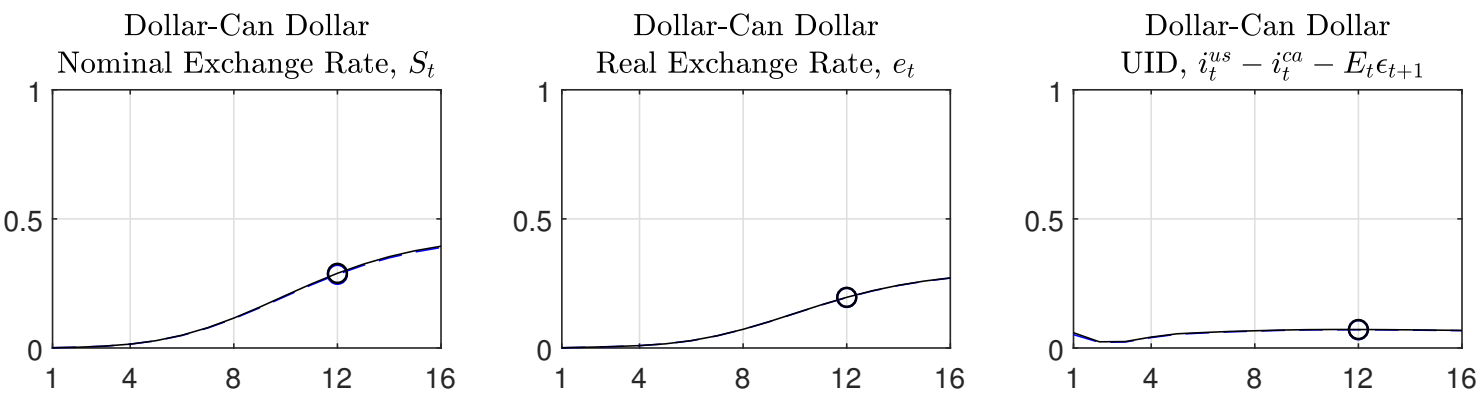

Notes: The horizontal axis indicates the forecasting horizon in quarters. The vertical axis measures the fraction of the forecasting error variance explained by $\Delta X_{t}^{m}$ (broken line) and by $\Delta X_{t}^{m}$ and $\Delta X_{t}^{m *}$ jointly (solid line). The circle indicates the fraction of the forecast error variance at forecasting horizon 12 quarters, which is the one shown in table 2 in the body of the paper. 


\section{References}

Azevedo, João Valle e, João Ritto, and Pedro Teles, "The Neutrality of Nominal Rates: How Long is the Long Run?," Working Paper w201911, Banco de Portugal, Economics and Research Department, 2019.

Backus, David, Patrick Kehoe, and Finn Kydland, "International Business Cycles: Theory and Evidence," in T. Cooley (ed.), Frontiers of Business Cycle Research, Princeton University Press, 1995, 331-356.

Bjørnland, Hilde C., "Monetary policy and exchange rate overshooting: Dornbusch was right after all," Journal of International Economics 79, 2009, 64-77.

Christiano, Lawrence J., Martin Eichenbaum, and Charles L. Evans, "Nominal Rigidities and the Dynamic Effects of a Shock to Monetary Policy," Journal of Political Economy $113,2005,1-45$.

Clarida, Richard, and Jordi Galí, "Sources of real exchange-rate fluctuations: How important are nominal shocks?," Carnegie-Rochester Conference Series on Public Policy 41, 1994, $1-56$.

De Michelis, Andrea, and Matteo Iacoviello, "Raising an inflation target: The Japanese experience with Abenomics," European Economic Review 88, 2016, 67-87.

Dornbusch, Rüdiger, "Expectations and Exchange Rate Dynamics," Journal of Political Economy 84, December 1976, 1161-1171.

Eichenbaum, Martin, and Charles L. Evans, "Some Empirical Evidence on the Effects of Shocks to Monetary Policy on Exchange Rates," Quarterly Journal of Economics 110, November 1995, 975-1009.

Engel, Charles, "Exchange Rates, Interest Rates, and the Risk Premium," American Economic Review 106, February 2016, 436-474.

Fanelli, Sebastian, and Ludwig Straub, "A Theory of Foreign Exchange Interventions," unpublished manuscript, Harvard University, 2019.

Faust, Jon, and John H. Rogers, "Monetary policy's role in exchange rate behavior," Journal 
of Monetary Economics 50, 2003, 1403-1424.

Faust, Jon, John H. Rogers, Eric Swanson, and Jonathan H. Wright, "High Frequency Financial data: Identifying the Effects of Monetary Policy Shocks on Exchange Rates Using High Frequency Data," Journal of the European Economics Association 1, September 2003, 1031-1057.

Gabaix, Xavier, and Matteo Maggiori, "International Liquidity and Exchange Rate Dynamics," Quarterly Journal of Economics 130, August 2015, 1369-1420.

Galí, Jordi, Monetary Policy, Inflation, and the Business Cycle, Princeton University Press: Princeton, NJ, 2015.

Galí, Jordi, and Tommaso Monacelli, "Monetary Policy and Exchange Rate Volatility in a Small Open Economy," Review of Economic Studies 72, 2005, 707-734.

Hamilton, James D., Time Series Analysis, Princeton University Press: Princeton, NJ, 1994.

Hassan, Tarek A., "Country Size, Currency Unions, and International Asset Returns," Journal of Finance 68, December 2013, 2269-2308.

Hassan, Tarek A., and Rui C. Mano, "Forward and Spot Exchange Rates in a Multi-Currency World," Quarterly Journal of Economics 134, 2019, 397-450.

Hettig, Thomas, Gernot Müller, and Martin Wolf, "Exchange Rate Undershooting: Evidence and Theory," unpublished manuscript, University of Tübingen, 2019.

Iskrev, Nicolay, "Local Identification in DSGE Models," Journal of Monetary Economics 57, 2010, 189-210.

Itskhoki, Oleg, and Dmitry Mukhin, "Mussa Puzzle Redux," unpublished manuscript, University of Wisconsin-Madison, July 2019.

Kim, Seong-Hoon, Seongman Moon, and Carlos Velasco, "Delayed Overshooting: Is It an 80s Puzzle?," Journal of Political Economy 125, 2017, 1570-1598.

Kim, Soyoung, and Nouriel Roubini, "Exchange rate anomalies in the industrial countries: A solution with a structural VAR approach," Journal of Monetary Economics 45, 2000, 
$561-586$.

Kollmann, Robert, "Macroeconomic effects of nominal exchange rate regimes: new insights into the role of price dynamics," Journal of International Money and Finance 24, 2005, 275-292.

Lustig, Hanno, and Adrien Verdelhan, "The Cross Section of Foreign Currency Risk Premia and Consumption Growth Risk," American Economic Review 97, March 2007, 89-117.

Mueller, Philippe, Alireza Tahbaz-Salehi, and Andrea Vedolin, "Exchange Rates and Monetary Policy Uncertainty," Journal of Finance 72, June 2017, 1213-1251.

Mussa, Michael, "Nominal Exchange Regimes and the Behavior of Real Exchange Rates: Evidence and Implications," Carnegie-Rochester Conference Series On Public Policy 25, $1986, \quad 117-214$.

Richmond, Robert J., "Trade Network Centrality and Currency Risk Premia," Journal of Finance 74, June 2019, 1315-1361.

Schmitt-Grohé, Stephanie, and Martín Uribe, "Closing Small Open Economy Models," Journal of International Economics 61, October, 2003, 163-185.

Schmitt-Grohé, Stephanie, and Martín Uribe, "Online Appendix to 'Exchange Rates and Uncovered Interest Differentials: The Role of Permanent Monetary Shocks'," unpublished manuscript, Columbia University, 2020.

Scholl, Almuth, and Harald Uhlig, "New evidence on the puzzles: Results from agnostic identification on monetary policy and exchange rates?," Journal of International Economics $76,2008,1-13$.

Sims, Christopher, and Tao Zha, "Error Bands for Impulse Responses," Econometrica 67, 1999, 1113-1156.

Uhlig, Harald, "What are the effects of monetary policy on output? Results from an agnostic identification procedure," Journal of Monetary Economics 52, 2005, 381-419.

Uribe, Martín, "The Neo-Fisher Effect: Econometric Evidence from Empirical and Optimizing Models," NBER working paper 25089, September 2018. 
Wiriadinata, Ursula, "External Debt, Currency Risk, and International Monetary Policy Transmission," unpublished manuscript, IMF, February 17, 2020.

Yakhin, Yossi, "Breaking the UIP: A Model-Equivalence Result," unpublished manuscript, Bank of Israel, March 2020.

Zhang, Tony, "Monetary Policy Spillovers through Invoicing Currencies," unpublished manuscript, Boston University, March 2020. 